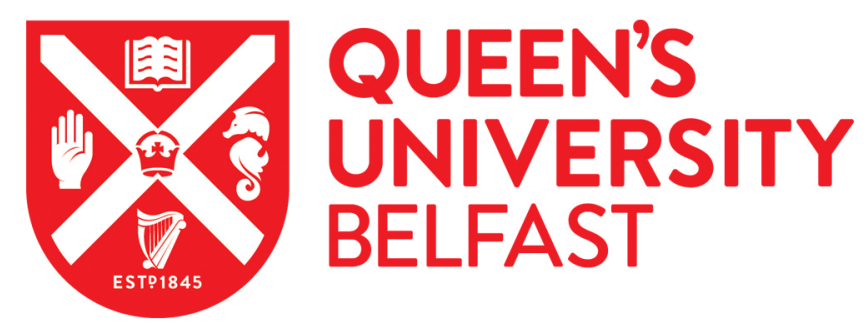

\title{
Granulation of teawaste and limestone using sodium-based lignosulfonate and DEM simulation of powder mixing Author links open overlay panel
}

Mangwandi, C., JiangTao, L., Chen, H., \& Albadarin, A. B. (2020). Granulation of teawaste and limestone using sodium-based lignosulfonate and DEM simulation of powder mixing Author links open overlay panel. Powder Technology. https://doi.org/10.1016/j.powtec.2020.11.009

Published in:

Powder Technology

Document Version:

Peer reviewed version

Queen's University Belfast - Research Portal:

Link to publication record in Queen's University Belfast Research Portal

\section{Publisher rights}

Copyright 2020 Elsevier.

This manuscript is distributed under a Creative Commons Attribution-NonCommercial-NoDerivs License

(https://creativecommons.org/licenses/by-nc-nd/4.0/), which permits distribution and reproduction for non-commercial purposes, provided the author and source are cited.

\section{General rights}

Copyright for the publications made accessible via the Queen's University Belfast Research Portal is retained by the author(s) and / or other copyright owners and it is a condition of accessing these publications that users recognise and abide by the legal requirements associated with these rights.

Take down policy

The Research Portal is Queen's institutional repository that provides access to Queen's research output. Every effort has been made to ensure that content in the Research Portal does not infringe any person's rights, or applicable UK laws. If you discover content in the

Research Portal that you believe breaches copyright or violates any law, please contact openaccess@qub.ac.uk. 


\title{
Granulation of teawaste and limestone using sodium-based lignosulfonate and DEM simulation of powder mixing
}

\author{
Jiangtao Liu ${ }^{1}$, Haili Chen ${ }^{1}$, Ahmad B. Albadarin ${ }^{2,3}$, Chirangano Mangwandi ${ }^{*}$ \\ ${ }^{1}$ School of Chemistry and Chemical Engineering, Queen's University Belfast, Belfast BT9 5AG, \\ Northern Ireland, UK \\ ${ }^{2}$ Laboratory of Theoretical and Computational Biophysics, Ton Duc Thang University, Ho Chi Minh \\ City, Vietnam \\ ${ }^{3}$ Faculty of Applied Sciences, Ton Duc Thang University, Ho Chi Minh City, Vietnam
}

\begin{abstract}
Co-granulation of teawaste with limestone was investigated using sodium-based lignosulfonate as a binder. A quality by design (QbD) approach was employed to formulate models for predicting the granule mean size, granule strength, limestone and binder uniformity from the process, and formulation variables. The results showed that teawaste volume fraction and liquid to solid ratio had a greater effect than other variables on granule mean size. Increasing teawaste in a binary mixture had a negative effect on granule mean size but positive effect on granule tensile strength. Limestone and binder uniformity could be increased by using higher impeller speed. DEM simulation showed that the impeller speed had a significant effect on the mixing quality and light particle fraction could significantly affect the fluctuation of the mixing index at the equilibrium stage. X-ray micro-computer tomography was applied as a technique to see the internal structure of the granules produced.
\end{abstract}

Keywords: Wet Granulation; Quality by Design; Experimental design; Powder Formulation; Quality Attributes. 


\section{Introduction}

High shear wet granulation is a size enlargement process which is used by several industries to produce granular products with improved functional properties from powdery materials. Size enlargement is initiated by the addition of liquid binder which wets the powder material and acts as a bonding agent. Wet granulation manufacturing processes can be complex and controlled by multi-factorial relationships between materials and process parameters [1-6]. It has been reported that the granule properties were affected by the relative composition of initial feed materials [3]. Binder properties like binder concentration and the mass of the binder used were found to be important factors that can significantly affect the final granules size distribution and granules properties $[3,4,7,8]$. A clear understanding of how changes in the formulation or process variables affect the final product quality is very important in order to reduce waste produced during the process. Design of Experiment and multivariate analysis has been used in the past to establish the design space in which the granulation process would result in the production of a product with desired attributes and develop correlations between the product attributes and input variables [9-14]. The pharmaceutical industry has adopted the concept of Quality by Design has been used to produced solid dosage forms with desired functionality $[9,13-18]$.

In the pharmaceutical industry, wet granulation is used to agglomerate multicomponent mixtures composed of excipient, binder, active ingredients, and disintegrants to produce an agglomerated product with desired flow characteristics, mechanical strength and composition. Application of multicomponent granulation is not only limited to pharmaceutical industry but has found application in other industries such as food $[6,19,20]$ and fertilizer industries $[1,11$, 21-24].

Despite several years of research on the topic there a numerous fundamental questions which remain unresolved in single component wet granulation systems due to the complexity of the granulation process; there are several rate processes that occur simultaneously, for instance, wetting nucleation, coalescence and consolidation breakage [25]. The level complexity is further increased when the formulation is composed of several powder components with differing physical and chemical properties as is the case in multicomponent granulation. In the pharmaceutical industry, the purpose of granulation is not only size- enlargement but to improve the mixing of the components in the preparation of the subsequent tablet formation. 
These challenges might have limited the attention given to multicomponent granulation in literature.

One of the challenges faced in multicomponent granulation is ensuring the homogenous distribution of the components across the product. There are several articles in literature discussing this topic from a pharmaceutical industry point of view [13, 18, 26-29]. Most of the articles in the literature focus on the homogeneity of pharmaceutical active ingredient (API) or homogeneity of the binder used in the granulation process. Differences in density, particle size, and wettability of the powder components can promote inhomogeneity of the components due to segregation or preferential wetting during granulation [4, 26, 27, 29-31]. Discrete element modelling (DEM) has been used in the past to study the mixing of powder and evaluate the segregation of powders [7, 32-37]. DEM is a numerical simulation tool which is capable of mimicking complex flow pattern by tracking each of the powder particles as individual entities throughout the whole mixing simulation. The effect of process parameters and formulation parameters on the mixing efficiency can be investigated through the use of DEM simulation.

In other industries granulation also allows mixing of different powder components which have different functionalities in the formulation. For example in our previous work [3, 23], we proposed a soil conditioner produced by co-granulation of limestone and biomass material (teawaste); where it was envisaged that both components would act synergistically to improve the quality of acid soils; limestone serves the purposed of being a $\mathrm{pH}$ controller and biomass increase organic matter of the soil [38]. One of the main challenges faced was ensuring homogeneous distribution of the components in the product due to increased likely wood of segregation of the components. As teawaste usually has a low bulk density, which could raise many problems during transportation, storage and utilisation, co-granulation of the teawaste with limestone can be a feasible way to produce a value-added soil conditioner/fertiliser. However, the difference in the physical properties of the components presents challenges as the component had different wettability, densities and particle sizes. In previous work, the physical properties of the limestone and teawaste powder were not altered as the goal was investigated the feasibility of the process and identifying suitable binder and process conditions that would lead to granular product of desired size and strength. Though successful granulation was achieved, granule strength was found to the lower than required to survive handling operations and minimise caking during storage. The distribution of the binary components across the different size classes was not investigated. 
Therefore, in this study, the co-granulation of teawaste with limestone would be investigated using the other binder sodium-based lignosulfonate. To reduce the segregation potential of the binary components, the teawaste was milled to match the size distribution of the limestone powder. The experimental design was employed to formulate models for predicting the granule mean size, granule strength, and component uniformity from the process and formulation variables. The effect of different powder formulation and impeller speed on the dry powder mixing procedure was investigated by using DEM. X-ray micro-computer tomography was applied as a technique to see the internal structure of the granules produced. Our work outlined a viable application of teawaste as a new substrate in soil conditioner, which would provide an economic and environmental method of disposing of piles of teawaste in the world.

\section{Material and methods}

\subsection{Materials}

Limestone powder was obtained from Killwaughter Chemicals Ltd, UK. Teawaste was supplied by Tesco and graded by ball milling before experiments. The particle size distribution of the limestone and teawaste powder after milling measured by Camsizer is shown in Figure $\mathrm{S} 1$ in the supplementary data, and the mean size of the limestone and teawaste powder was 240 $\pm 30 \mu \mathrm{m}$ and $284 \pm 12 \mu \mathrm{m}$, respectively. The pouring density of limestone and teawaste powder is $1 \mathrm{~g} / \mathrm{mL}$ and $0.5 \mathrm{~g} / \mathrm{mL}$, respectively. Sodium-based lignosulfonate supplied by Borregaard, Norway was used to make binder solutions. Aqueous solutions with desired binder concentrations were prepared by adding different amounts of the lignosulfonate powder into a certain volume of deionised water. Illustration of the granulation process is shown in Figure $\mathrm{S} 2$.

\subsection{Experimental design}

$2^{\mathrm{K}}$ factorial design of experiment was used to establish the influence of process and formulation variables on the granule properties. Each variable was varied at two levels; low level (-1) and high level (+1). For binder concentration (BC), the two levels were 0.2 and $0.4 \mathrm{~g} / \mathrm{l}$; for teawaste volume fraction (the volume of teawaste/the total volume of powder mixture, TF), the two levels were 0.3 and 0.6; for impeller speed $(\mathrm{O})$, the two levels were $103 \mathrm{rpm}$ and $158 \mathrm{rpm}$; and for liquid to solid ratio (the binder volume/the total volume of powder mixture, LS), the two levels were 0.25 and 0.3. The list of the experiments is shown in Table 1. Ex-1, Ex-2, Ex-3, Ex-4, Ex-5 and Ex-6 stand for the experiments taken under Ex conditions but with different 
time endpoints GT (30 s, 60 s, 90 s, 120 s, 150 s, and 180 s). The responses from these experiments are mean size of granules at different endpoints, granule tensile strength, limestone uniformity and binder uniformity.

\subsection{Granulation procedure}

The desired amount of limestone powder and teawaste was weighed according to Table 1 and transferred into the granulator Kenwood- KM070 (Kenwood, UK). This binary mixture was firstly pre-mixed for one minute at an impeller speed of $76 \mathrm{rpm}$, then a certain pre-measured lignosulfonate binder was pumped into the granulator by a peristaltic pump with a flow rate of $60 \mathrm{ml} / \mathrm{min}$. The binder was added while the impeller was in motion. After the binder addition stage, the granulator was stopped to allow removal of caking from the impeller and the walls of the vessels. Granulation was continued under conditions according to Table 1. After granulation, the granules were oven-dried at $60{ }^{\circ} \mathrm{C}$ for 12 hours and then stored in sealed plastic bags for further analysis.

\subsection{Size analysis and tensile strength test}

The method of granule mean size analysis was the same as that described in [3], and the granule tensile strength test is based on the procedure described in [22].

\subsection{Granule composition analysis across different sizes and the determination of granule uniformity}

Table 2 shows a summary of the concentrations of elements in three raw materials used in this work. The concentration of calcium in limestone is about 150 times of that in the binder (lignosulfonate), while the concentration of sodium in the binder is about 800 times that in limestone powder. Due to this calcium and sodium were selected as the element to monitor limestone and lignosulfonate concentration in dry granules, respectively. The analysis method was presented in Method $1 \mathrm{ESI}$, and the concentration (in $\mathrm{g} / \mathrm{g}$ ) of the limestone and lignosulfonate in the dry samples was calculated using Eq. (1) and Eq. (2) as follows, respectively.

$$
\begin{gathered}
C_{\text {lime }}=\frac{\alpha C_{\text {CaS }} V_{\text {sample }}}{C_{\text {CaL }} m_{\text {sample }}} \\
C_{\text {lig }}=\frac{\alpha C_{\text {NaS }} V_{\text {sample }}}{C_{\text {NaL }} m_{\text {sample }}}
\end{gathered}
$$


where $C_{\text {lime }}$ and $C_{\text {lig }}$ are the concentrations of limestone and lignosulfonate in dry granules, respectively; $\alpha$ is the dilution factor; $C_{\mathrm{CaS}}$ and $C_{\mathrm{NaS}}$ are the calcium and sodium concentration in the sample, respectively; $V_{\text {sample }}$ is the volume of the sample; $m_{\text {sample }}$ is the mass of the sample; $C_{C a L}$ and $C_{N a L}$ are the calcium concentration in limestone and the sodium concentration in lignosulfonate (Table 2), respectively.

The de-mixing potential was used as a measure of homogeneity of limestone or lignosulfonate in dry granules across different sizes in this work. The de-mixing potential of limestone content or lignosulfonate content across different sizes is calculated using Equation (3).

$$
D P(\%)=\frac{100}{\bar{p}} \sqrt{\sum \frac{w\left(p_{i}-\bar{p}\right)^{2}}{100}}
$$

where $\bar{p}$ is the average concentration, $w$ and $p_{i}$ are the weight and actual concentration of the particular sieve fraction, respectively[27].

\subsection{DEM simulation}

The simulation theory is presented in ESI. In this section, particles with the same size but different density (heavy and light particles referring to limestone and teawaste, respectively) were employed to simulate teawaste and limestone mixing. The particle size used in this work was $2 \mathrm{~mm}$, which was much larger than the initial particle size of teawaste and limestone. The reason for choosing such big particles was that the time required to complete simulation increased significantly for small particle sizes. The vessel and impeller used in this work are shown in Figure 1(a). The geometry of the vessel and impeller was the same as that of the granulator vessel in the laboratory and the scale is 1:1. The top and bottom inner diameter of the vessel is $230 \mathrm{~mm} 130 \mathrm{~mm}$, respectively. The height of the vessel is $140 \mathrm{~mm}$. The impeller is vertical to the vessel base and has no contact with the bottom base. The vessel and impeller used in this work is made of stainless steel. The initial arrangement of particles in the vessel is top-bottom segregated as shown in Figure 1(b).

The parameters (properties of light particles, heavy particles and stainless steel) used in the simulation are shown in Table 3, and 4 cases of simulation (Table 4) have been conducted, which were designed to examine the effects of impeller speed and light particles to heavy particles ratio that characterised a binary mixture. For each simulation, particles were generated in the vessel layer by layer until the required number of particles was generated. Once all the 
particles had settled down, the motion of the impeller at the pre-set speed was initiated and kept constant for the required mixing time.

\section{[Figure 1 here]}

\subsubsection{DEM simulation results analysis}

Lacey's mixing index was used as an indicator of mixture quality. It has been reported in the literature that Lacey's mixing index could successfully be used to correlate the effect of particle density on mixture quality[39]. For a binary mixture, the composition homogeneity can be expressed by the mixing index, as follows[40]:

$$
M=\left(\frac{S_{o}^{2}-S^{2}}{S_{o}^{2}-S_{R}^{2}}\right)
$$

where $S_{o}^{2}$ is the variance of a completely segregated mixture, $S_{R}^{2}$ is the sample variance of completely randomly mixed mixture and $S^{2}$ is the sample variance of a mixture that is between fully random and completely segregated state.

$$
\begin{aligned}
& S_{o}^{2}=p q \\
& S_{R}^{2}=\frac{p q}{N} \\
& S^{2}=\frac{1}{N} \sum_{i=1}^{n}\left(p_{i}-\bar{p}\right)^{2}
\end{aligned}
$$

In the above equations $p$ and $q$ are the fractions of the two components in the mixture and $N$ is the total number of particles in the sample, $p_{i}$ is the concentration of the species $\mathrm{A}$ in the $i^{\text {th }}$ sample and $\bar{p}$ is the average concentration and $n$ is the number of samples. The Lacey index takes values between 0 and 1; a mixing index of 0 would indicate a completely segregated mixture while 1 would indicate a perfectly mixed mixture[41].

\subsection{X-Ray tomography of samples}

Single granule samples were scanned using a commercial desktop XPT system (Specimen $\mu \mathrm{CT}$ 35 X-ray Microtomography). All the samples were micro-tomographed with an x-ray beam of $55 \mathrm{kv}$ and $145 \mathrm{uA}$. Two hundred and forty X-ray images were recorded in a parallel projection geometry for each sample and the integration time for each projection was $1000 \mathrm{~ms}$. Tomographic reconstruction was performed by using ImageJ software and 2048× 2048 pixels 
cross sectional images were obtained. One pixel is equivalent to $3.5 \times 3.5 \mu \mathrm{m}$. The binder content in the granules was calculated using the following equation:

$$
C_{b}=\frac{V_{\text {void }}}{V_{\text {total }}} \times 100 \%
$$

where $V_{\text {void }}$ is number of voxels regarded as void in the sample, $V_{\text {total }}$ is the total voxels in the sample and $C_{b}$ is the binder content in the sample.

\section{Results and discussion}

\subsection{Effect of process and formulation variables on granule mean size}

The summary of the mean granule size is shown in Figure S3. Two experiments were failed since the system was over-wetted and formed a paste. The granule mean size resulting from 14 batches showed the highest mean size was obtained from batch E1-3 (3.12 mm) and E15-3 $(2.92 \mathrm{~mm})$. The mean size of granules produced is affected by both the process variables $(\mathrm{O}$ and GT) and the formulation variables (LS, BC and TF). The granule mean size at a given granulation time can be expressed in terms of coded variables. For instance, the mean size of granules produced at the time endpoint $t$ could be expressed as:

$$
d_{t}=b_{0}+b_{1} A+b_{2} B+b_{3} C+b_{4} D+b_{5} A B+b_{6} B D
$$

where A, B, C and D are the coded variables for BC, TF, O and LS, respectively (A, B, C and $\mathrm{D}$ are coded or normalised variables such that the maximum value is represented by +1 and minimum value by -1$)$.

The coefficients which were related to coded variables for the granule mean size at the time endpoint of 30, 60, 90, 120, 150 and 180 seconds are shown in Table 4. It was observed that the maximum value of coefficient obtained was the coefficient of term $B$, followed by term $D$, which suggested that the effect of TF and LS on granule mean size was greater than other variables.

Summary of the coefficients of TF and LS is presented in Figure 2. In the set of 6 experiments that were carried out, the range of values of the variables were the same. Therefore, for each model term in the equation, the magnitude of its coefficient was proportional to its contribution to the change in the response variable (granule mean size). It can be seen from Figure 2 that the coefficient values of TF and LS decreased with increasing granulation time. These effects 
became smaller when the granulation time increased, which indicated the contribution of formulation variables on the granulation process becomes less with increasing granulation time. Since the results obtained from experimental design and the effect of these variables on granule mean size showed the same trends at different time endpoints, attention was more focused on results of mean granule size at the time endpoint of 90 seconds $\left(d_{90}\right)$.

\section{[Figure 2 here]}

Detailed ANOVA analysis results of the effect of different variables on the granule mean size at the endpoint of 90 seconds are given in Table 5. Judging from P-values presented in Table 5, the Interaction Model adequately described the dependence of granule mean size on the independent variables since the P value for the model was less than 0.0001 . A P value less than 0.05 indicates that model terms are significant. In this case, the most significant model terms in this equation were $\mathrm{BC}, \mathrm{TF}, \mathrm{O}, \mathrm{LS}, \mathrm{BC}-\mathrm{TF}$ interaction and TF-LS interaction terms.

The effects of different process variables on granule mean size are summarised by the surface plots in Figure 3. At low level of TF (0.3), increasing binder concentration would increase granule mean size. Increasing the BC increases the binder viscosity, which means the viscous forces between primary particles increase, resulting in formation of stronger liquid bond between particles that are more difficult to break. On the other hand, more viscous binder decreases binder distribution in the powder bed. Larger nuclei are formed during the nucleation which causes larger granule mean size. Similar trends could be observed from both Figure 3(a) and Figure 3(b) where the granule mean size decreased with the increasing of TF. This could be explained by the low wettability of teawaste powder compared to limestone powder. From our previous work, it was found that teawaste powder showed a higher contact angle to water solution when compared to limestone, which implied low wettability .With the increasing percentage of teawaste powder in the binary mixture, the wettability of the mixture would decrease. This made the surface wetting step more difficult, which then resulted in difficulties in nucleation. Under the experimental conditions, even though the BC increased from $0.2 \mathrm{~g} / \mathrm{L}$ to $0.4 \mathrm{~g} / \mathrm{L}$, the granule mean size did not show any changes when the high level of TF (0.6) was used. Moreover, since teawaste powder is more porous than limestone powder [20], binder droplets need to fill these pores first before getting the powder surface saturated. In this case, increasing TF could increase the amount of binder consumed for filling pores, which would lead to less binder availability for nucleation. 
It is interesting to see how impeller speed had a negative effect on granule mean size (see Figure 3(a)), which was opposite of the trends obtained from previous studies [2, 42]. This was due to the different time period we focused on. Most previous studies focused on the effect of impeller speed during the granule growth period. In contrast, these series of experiments were investigating the granule breakage period. The existence of the binder addition stage caused nucleation and most growth periods happened during this stage. During the growth period, increasing the impeller speed can increase the rate of granule consolidation. However, in the breakage stage, increasing the impeller speed increases both shear rate between granules and shear rate between granules and wall, gives more opportunity for granules to break down. LS has been reported as one of the most important variables by previous studies [8, 22]. Figure 3(b) presents the effect of LS on granule mean size. It shows an expected trend as increasing LS would result in larger granule mean size. Increasing LS increases the chances for powder and binder sticking together. In this case, powders are more likely to form nuclei for further agglomeration. It is worth noting that, for most granulation systems, there is a critical amount of liquid binder that needs to be added into the system to ensure successful granulation and this critical value changes according to the other variables. Excess addition of binder would result in paste formation, as was observed in experiments E3-3 and E5-3.

\section{[Figure 3 here]}

\subsection{Effect of process and formulation variables on granule tensile strength}

It is shown that the maximum granule tensile strength, $9.71 \mathrm{MPa}$, was obtained when all the variables were at their maximum values (full results are shown in Table S1). The minimum granule tensile strength was obtained from batch 25 (0.76 MPa), where the BC, TF, LS and GT were at their low levels. ANOVA analysis was performed using the Design Expert software to explore the influence of the variables on the strength. The granule tensile strength of granules could be expressed as coded variables:

$$
\sigma=3.76+2.11 A+0.75 B+0.26 D+0.32 E+0.60 A B+0.23 A E-0.22 B D
$$

where A, B, D and E are the coded variables for BC, TF, LS and GT, respectively.

Detailed ANOVA analysis results of the effect of different variables on the granule tensile strength are given in Table 6. Judging from the $\mathrm{P}$ value obtained, the Interaction Model adequately described the dependence of granule strength on the independent variables since the $\mathrm{P}$ value for the model was less than 0.0001 , and the most significant model terms were $\mathrm{BC}$, 
TF and BC-TF. Notably, impeller speed was not included as a term in the equations (ANOVA analysis), which indicated that changing the impeller speed did not have a significant effect on granule strength. This could be explained by the proposed mechanism for the granule process. Since the binder was added to the system by pumping, the particles were closely packed and fully saturated during mixing. In this case, after a period of mixing, the probability of consolidation was low since the granules were already near their minimum porosity. Increasing the impeller speed increased the collisions, however the distance between particles was already quite small and little consolidation would take place, which implied the granules would be at approximately their maximum strength at the end of granulation. Consequently, the increase in impeller speed had little effect on granule tensile strength in this process, which was in agreement with previous researchers[43].

Figure 4 shows the effect of $\mathrm{BC}$ on granule tensile strength. The granule tensile strength was proportional to BC with different LS and TF. During the high shear wet granulation, particles are saturated by the binder and then consolidated by collision. Increasing the binder concentration increases the viscosity of the binder solution. With higher viscosity, the liquid bonds between particles become stronger. Consequently, increasing the binder concentration increases the granule tensile strength in this process. It can be seen from Figure 4 that, as TF increased, granule tensile strength increased. Based on our previous study[3], the wettability of the binary mixture would decrease (liquid to solid contact angle would increase) when the amount of teawaste in the binary mixture increased. According to the following equation developed by Rumpf [44], with increasing liquid to solid contact angle, the overall granule strength decreased.

$$
\sigma_{t}=\lambda \kappa \frac{1-\varepsilon}{\varepsilon} \frac{\gamma_{L V} \cos \theta}{d_{p}}
$$

where $\lambda$ is the liquid pore saturation, $\kappa$ is a material constant (for uniform spheres $K=6$ ), $\varepsilon$ is the granule porosity, $d_{p}$ the surface-average particle diameter, $\gamma_{L V}$ the liquid surface tension and $\theta$ is the liquid-solid contact angle.

In this study, the trend of the effect of TF on granule strength observed was opposite to the trend observed from Rumpf's equation. This could be explained by the definition of teawaste volume fraction. As described in Section 2.1 and 2.2, the TF was the volume ratio of teawaste to total powder volume, and the pour density of teawaste powder is half that of limestone powder. Therefore, as the TF increases, the mass of total powder would decrease. In this case, 
keeping the other parameters constant at the same level, the mass to mass liquid to solid ratio would increase with increasing TF. More liquid bonds could form between primary particles at higher level of TF, which would then affect the overall granule strength.

\section{[Figure 4 here]}

As shown in Figure 4(a), granules produced with higher LS had higher tensile strength. Granules strength is controlled by three forces: capillary, viscous and frictional force[25]. During the granulation process, although increasing the LS while keeping other variables as constant increases the amount of binder added to the system, the capillary and viscous force between particles and binder stays at the same level since the type and concentration of binder are not changed. With more binder added to the system, more solid bonds would form after the drying process. This increases the frictional forces between primary particles and binder, which would further increase the overall strength of the granules. When the low level of BC was used during the granulation process, GT had no significant effect on granule strength (Figure 4(b)), however, at high level of BC, GT had a positive effect on granule strength. When the granulation process was operated at a low level of $\mathrm{BC}$, binder viscosity was lower compared to that of a higher level of BC. With lower binder viscosity, binder was more easily mixed well with powder particles. Since the low level of GT was long enough to make the distance between particles to the minimum, further increasing GT would not have a significant effect on granule strength. When the granulation process was operated at a high level of BC, binder was more difficult to be delivered compared to that with a low level of BC. Increasing the GT would give enough time for consolidation, which would further increase the granule strength[25].

\subsection{Effect of process and formulation variables on limestone uniformity}

The uniformity of the limestone and lignosulfonate in the granules was analysed using the demixing potential as discussed in section 2.4. Detailed ANOVA analysis results of the effect of different variables on the limestone de-mixing potential using Design Expert software are given in Table S2. The limestone de-mixing potential of granules could be expressed as coded variables:

$$
\begin{aligned}
& D P_{\text {Lime }} \%=8.65+1.33 A+3.44 B+2.90 C-0.28 D+1.04 A B-0.16 A C+0.0029 A D+3.80 \mathrm{~B} C- \\
& 0.84 B D-0.55 C D
\end{aligned}
$$

where A, B, C and D are the coded variables for BC, TF, O and LS, respectively. 
Judging from the $\mathrm{P}$ value 0.0009 , the 2 -Factor interaction model adequately described the dependence of granule limestone de-mixing potential on the independent variables, and the most significant model terms were BC, TF, O, BC-TF, TF-O and TF-LS.

The effect of BC on limestone de-mixing potential is illustrated in Figure 5(a). The maximum and minimum limestone de-mixing potentials were around $22.5 \%$ and $2.15 \%$, respectively. It can be seen that the limestone de-mixing potentials operated under low $\mathrm{BC}$ conditions were lower than those operated under high $\mathrm{BC}$ conditions, which indicated that increasing the $\mathrm{BC}$ had a negative effect on limestone uniformity in granules. A binder with a high concentration of binder is more viscous than one with a lower concentration so stronger liquid bonds are formed between primary particles when the binder interacts with powder primary particles. It has been reported by previous researchers that breakage of granules during the granulation process improved the material exchanges which further promoted the granule uniformity [4, $27,31]$. It was expected that decreasing the $\mathrm{BC}$ could decrease the granule strength, which would promote breakage during the granulation process. In this case, decreasing the BC would result in more material exchanges occurring and more homogeneity granules formed. With the increasing of LS used during experiments, two opposite trends of changing de-mixing potential of limestone content in granules were observed. When the amount of binder added to the system increased, the modification of limestone de-mixing potential depended on both the destructive force and the constructive force. Increasing the LS used during the process increased the availability of binder. With higher binder availability, more primary particles could be involved in the granulation process, which had a positive effect on granule uniformity. On the other hand, increasing the LS resulted in more liquid bonds being formed between primary particles, which reduces granules breakage. With less granule breakage during the granulation process there will be less material exchanges, which then manifest as content heterogeneity or less uniformity.

The limestone distribution in granules produced under different LS is shown in Figure 5(b). For granules produced under low level of LS, limestone content in granules presented a peak around size range 0.5 to $0.7 \mathrm{~mm}$. For those produced with high LS, the peak exhibited at around size range 1.4 to $1.7 \mathrm{~mm}$. The figure also shows that $50 \%$ of the limestone was in granules under the size of $0.7 \mathrm{~mm}$ when LS was 0.25 , however, when LS increased to $0.3,50 \%$ of limestone was found in granules with a size under $0.9 \mathrm{~mm}$. The size distribution of granules produced under low LS showed that almost half the mass of granules was in the size range 
under $0.5 \mathrm{~mm}$. In this case, limestone exhibited a high-level content in those fine granules. With increasing amount of binder added into the system, fine granules in size range 0 to 0.5 $\mathrm{mm}$ grew into the larger class. As discussed in Section 3.1, limestone presented lower contact angle to water solution, which indicated higher wettability. It has been reported by previous researchers that difference in primary particles' wettability would cause selective nucleation and consequently growth of the superior wetting primary powders in the binary mixture[45, 46]. Limestone powder had a higher probability of enlarging to the higher size range, which resulted in a decrease of limestone content in a low size range but an increase in the limestone content in the middle size range.

\section{[Figure 5 here]}

The compositions of the top (layer 2) and bottom layer (layer 1) of the powder bed dry mixing under different conditions obtained from DEM simulation are illustrated in Figure 6. The percentage of teawaste particles in the top layer showed a trend of increasing then reaching an equilibrium level, while the percentage of teawaste particles in the bottom layer showed a trend of decreasing then approaching an equilibrium level. This was because teawaste particles were added to the vessel followed by the limestone particles, which implied that the majority of teawaste particles were settled at the bottom layer before mixing. All figures show that the percentage of tea particles in the top layer was higher than the theoretical value. This suggested the top layer of the powder bed is potent with respect to the teawaste particles, which indicated that the percentage of limestone powder in the top layer was in a vulnerable position. The binder was pumped into the system, then the powder bed was first wetted from the top. At the time binder droplets fell on the powder bed, it was disproportionately more possible to be surrounded by teawaste particles than by limestone particles. Dry powder mixing and segregation in the granulator have been studied by previous researchers [29, 47]. De-mixing of powder component was observed when there was a difference between the densities of the primary particles. The lighter particles would drift to the top of the powder bed, while the denser particles settled at the bottom of the powder bed. This was in agreement with a commonly known phenomena called percolation or sieving segregation. As shown earlier in Figure 5(a), TF had a complex effect on limestone de-mixing potential. Combined with the other different experimental conditions, increasing TF would result in a different trend of limestone de-mixing potential which was consistent with the previous ANOVA analysis results which indicate that BC-TF and TF-O are very significant model terms. For example, when the high level of $\mathrm{O}$ and low level of LS were used, increasing the TF had a positive effect on limestone content de-mixing potential, which indicated a decrease in limestone uniformity. As 
shown before, this was due to the top layer of powder bed containing less limestone than the theoretical value which gave a higher probability of teawaste particles forming nuclei. Increasing the TF decreased the percentage of limestone in the top layer, which resulted in a lower chance for limestone to be involved in the nucleus. Consequently, nuclei formed mainly by teawaste particles began to grow, which had a negative effect on limestone uniformity.

\section{[Figure 6 here]}

Increasing the impeller speed increased the frequency of collisions between particle and impeller, particles to vessel wall, and particles to particles resulting in more breakage during the process. It has been reported that granule breakage played an important role in granule homogeneity[31]. Intensive granule breakage would lead to a continuous exchange of primary particles and granules, which resulted in more homogeneous granules. Also, it can be seen from Figure 6 that the impeller speed has a positive effect of on limestone uniformity. The teawaste percentage in the top layer at equilibrium slightly decreased with increasing impeller speed, which indicated a promotion of limestone percentage in the top layer. With high rotating rates applied, the particles experienced a higher centrifugal force compared to gravitational force, which would bring some limestone particles from the bottom layer into the top layer. Thus, higher limestone percentage in the top layer increased the probability of limestone particles involving in nucleation, which further resulted in a decrease in limestone de-mixing potential. However, the final effect of the $\mathrm{O}$ on the limestone de-mixing potential also depends on the effects of other combined factors like the BC-TF and TF-LS.

\subsection{Effect of process and formulation variables on lignosulfonate binder}

The lignosulfonate de-mixing potential under different conditions is presented in Table S3 which showed that the maximum value was $11.25 \%$ and the minimum value was $5.21 \%$. Detailed ANOVA analysis results of the effect of different variables on the binder de-mixing potential using Design Expert software are given in Table S5. The de-mixing potential of the binder could be expressed as coded variables:

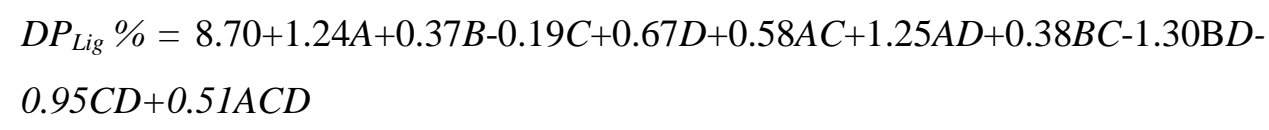

where $\mathrm{A}, \mathrm{B}, \mathrm{C}$ and $\mathrm{D}$ are the coded variables for $\mathrm{BC}, \mathrm{TF}, \mathrm{O}$ and LS, respectively. 
The Interaction Model adequately described the dependence of granule limestone de-mixing potential on the independent variables since the $\mathrm{P}$ value for the model was 0.0117 and the most significant model terms were BC, LS, BC-LS, TF-LS and O-LS.

The surface plot showing the effects of different variables on binder de-mixing potential is shown in Figure 7. Increasing binder concentration in the granulating fluid increased the viscosity of the fluid. The dispersion of binder of higher viscosity is more difficult compared to a less viscous binder, which means increasing the binder viscosity would result in a more inhomogeneous binder distribution. On the other hand, liquid bonds between primary particles formed with higher viscous binder are more difficult to break compared to those formed with lower viscous binder, which would decrease the frequency of material exchanges during granulation. Consequently, increasing the binder concentration used during the process had a negative effect on binder distribution, which was in agreement with what was obtained from Figure 7 where increasing the $\mathrm{BC}$ could increase the binder de-mixing potential when the low level of $\mathrm{O}$ and the high level of LS were used.

\section{[Figure 7 here]}

Increasing the LS applied during experiments, two opposite trends of changing binder demixing potential in granules were observed. With the low level of BC and the high level of TF used during granulation, increasing LS would result in a reduction in binder de-mixing potential. However, when the high level of BC and low level of TF were applied, the binder de-mixing potential increased with an increase in LS. As shown earlier, BC-LS and TF-LS were both quite significant model terms in this interaction model. These factors would interact with each other and would finally cause the two opposite trends observed. The results show the formulation variables (i.e. BC, LS and TF) had a significant effect on the homogeneity of the binder in the granules.

During the nucleation process, binder droplets need to fill the pores of primary particles before getting the surface wet, resulting in some of the binder droplets being trapped in particle pores. As shown in our previous publication[3], the specific pore volume of teawaste was ten times higher than that of limestone, which indicated teawaste particles required more binder to get surface wet compared to limestone particles. As shown earlier in Figure 6, increasing the TF in the binary mixture could increase teawaste percentage in the top layer of the powder bed. As 
discussed before, when a binder droplet fell into the powder bed, it was disproportionately surrounded by more teawaste particles. Increasing the probability of binder to be surrounded by teawaste particles increased the amount of binder consumed to fill teawaste pores; which caused a further decrease in binder uniformity. However, combined with the other experimental factors, increasing TF would result in different trends of binder de-mixing potentials which was consistent with the earlier ANOVA analysis results. As for the effect of the $\mathrm{O}$ on the binder uniformity, the result was quite similar to that of the limestone de-mixing potential. All the factors would interact with each other to form a different trend.

\subsection{Effect of process variables on dry powder mixing}

In this study, to measure the Lacey's mixing index, the mixing domain was discretised using a 10x10x10 mesh system, as shown in Figure S4. Earlier experimentation with different mesh considerations: $5 \times 5 \times 5,8 \times 8 \times 8,10 \times 10 \times 10$ and $12 \times 12 \times 12$ showed that the optimum mesh system was the 10x10x10 as further increasing the number of mesh elements provide no further benefit to the numerical analysis (please see Figure S5 for details). Since the majority of particles were settled at the bottom of the vessel, cells at the bottom two layers were taken as samples to calculate the Lacey's mixing index.

The impeller speed affects the particle flow in a high shear mixer. To examine the effect of impeller speed on particle segregation, the simulations were operated under two different levels of impeller speed (103 and $158 \mathrm{rpm}$ ). 4200 light particles and 1800 heavy particles of $3 \mathrm{~mm}$ diameter were added to the vessel by the top and bottom loading (light particles at bottom). Figure 8 shows the Lacey's mixing index versus time as a function of the impeller speed. It can be seen that the equilibrium mixing index was achieved faster at the higher impeller speed. The rotational speed of the impeller had a great effect on the time required to achieve the equilibrium mixing state $[32,36]$. This was due to the fact that increasing the impeller speed increased the movement of particles and the mixing cycles per unit time, resulting in a better mixing performance. It was also observed from Figure 8 that the equilibrium index obtained from low and high impeller was around 0.85 and 0.91 , respectively. The rotation speed of the impeller affected the particle flow in the mixer, resulting in different equilibrium mixing indices[32].

\section{[Figure 8 here]}


Figure 9(a) shows that the average vertical position of the heavy particles in the vessel. It can be seen that the average position of heavy particles after 20 seconds mixing was $10.9 \mathrm{~mm}$ and $14.7 \mathrm{~mm}$ from the bottom of the vessel at low level and high level of impeller speed, respectively. When the process operated at the high level of rotating speed, the impeller was able to bring more heavy particles from the bottom layer to the top layer of the powder bed, compared to the process operated at the low level of rotating speed. Increasing the impeller speed increased the average position of heavy particles from bottom of the vessel, resulting in a better mixing performance of the binary mixture. In order to measure the effect of light particle fraction on particle segregation, the simulations were operated under two different levels of light particle fraction (0.3 and 0.6), which was the same as the TF used in this study. 6000 particles with $3 \mathrm{~mm}$ diameter were added to the vessel according to different light particle fraction. The impeller speed was $158 \mathrm{rpm}$ and the initial loading was top and bottom loading (light particles at bottom). Figure 9(b) presents the mixing index versus time obtained from simulations using different light particle fraction. It is interesting to note that increasing the light particle fraction from 0.3 to 0.6 had no significant effect on the value of the mixing index but the fluctuations of the mixing index value at the equilibrium stage. Since the impeller speed was fixed, the input energy was the same for these simulations. It has been reported in previous literature that the light particles received a larger vertical force than the heavy particles[28]. Increasing the light particle fraction would decrease the total mass of particles. Decreasing the mass of particles in a sample cell would increase the average kinetic energy available per unit mass, which could result in a better mixing performance.

\section{[Figure 9 here]}

\subsection{Effect of process and formulation variables on granule structure}

In literature, most researchers considered the void in the sample as pores [48, 49]. Since the grey value of binder was close to that of the air in this work, the void in the samples was considered as binder. Figure S6 illustrates an image of granule structure obtained from X-ray tomography. It can be seen that the white particle marked out was not attached to any other particles. Due to the weight of the particle, it was impossible that the particle was not adhere to anything. This was the reason that the void in the sample was considered as binder. Summary of binder content calculated from X-ray tomography results is listed in Table 7. 
It can be seen that the highest and lowest binder content in the sample were obtained from sample 3 and sample 6, which were $25.5 \%$ and $3.37 \%$, respectively. It can be noted from Table 7 that calculated binder content of samples 5 to 8 were similar in value, ranging from about 3.3 to $4.7 \%$ which is to be expected considering the granulation liquid of the same concentration was used in producing these granules. Samples 2 and 4 were from batches with the same process conditions (i.e. O and GT) and same teawaste mass fraction, the only difference being the concentration of the binder used. When comparing the calculated values of the binder content, it is noted that the value for sample 4 is almost twice that of sample 2 . This is also to be expected since the binder concentration used for batch sample 4 was twice that of sample 2 . This proves that the concentration data from X-ray tomography are reliable. From the optical images of the samples shown in Figure 10(a) and (b), it can be seen that the images showed homogeneous greyscale intensities, with large regions of voids in the sample. However, there were still some voids towards the centre of the sample, which indicated some binder areas still presented in both samples. The calculated binder content obtained from samples produced under low and high level of impeller speed were $13.5 \%$ and $10.22 \%$, respectively. The only clear difference was on the shape. With increasing impeller speed used during the granulation process, the granule tended to adopt a more spherical shape due to the effect of the increased shear force in the granulator.

The central cross sections of samples under different granulation times are shown in Figure 10(c) and (d). After $30 \mathrm{~s}$ of granulation, the sample showed a more enlarged shape while after $180 \mathrm{~s}$ of granulation, the sample presented a more spherical shape. Both samples showed internal low-density materials in the sample, which corresponded to the sodium lignosulfonate binder used for the granulation. The presence of binder within granules could be explained by the high level of $\mathrm{BC}$ and the immersion mechanism during the nucleation process. For the sample produced under short granulation time, the regions of binder were at the centre of the granule. However, with increasing GT, the regions of binder went from the centre to the surface of the granule and it looked relatively homogeneous in all of the images. This homogeneous distribution of binder could be the result of breakage of nuclei. The other possibility for this phenomenon was the other small granules formed with small binder droplet that stuck to the surface of a bigger granule when its surface became wet enough after the liquid binder was squeezed out of the centre by the particles flowing into the binder droplet. In other word, the nucleation happened around the binder droplets. With increasing the granulation time, the size 
of binder droplet decreased due to penetration of primary particles and breakage of binder droplets. The overall binder content obtained from these two samples were $19.28 \%$ and $25.5 \%$ for samples produced under short GT and long GT, respectively. Figure 10(e) and (f) shows the images of central cross sections of samples at different LS. Granules made with LS 0.3 showed a smoother surface and shape. Increasing the LS increased the amount of binder available during the granulation, resulting in high moisture content in the granules. Increasing the moisture content in the granule increased the attrition rate[50]. With more attrition happening on the surface of granules, the shape of granule became rounder and the surface of granule became smoother. The overall binder contents in these two samples were similar: $3.81 \%$ and $4.34 \%$ for samples operated under low LS and high LS, respectively.

\section{[Figure 10 here]}

\subsection{Conclusion}

Granules with high strength were made by co-granulation of teawaste and limestone using sodium-based lignosulfonate as a binder. The granule mean size, granule strength, limestone uniformity and the binder uniformity are all affected by the binder concentration, teawaste fraction, impeller speed and the amount of binder added in the granulation process. Changing the formulation of the powder during mixing does not have a significant effect on the value of the mixing index, and the equilibrium mixing index can be achieved faster at the higher impeller speed. The impeller speed used during granulation could affect the shape of granules, while changing the liquid to solid ratio used changes the roundness and the surface roughness of granules. Granulation time can change not only granule shape but also the position of binder region. 


\section{References}

1. Walker, G.M., et al., Effect of process parameters on the crush strength of granular fertiliser. Powder Technology, 2003. 132(1): p. 81-84.

2. Mangwandi, C., et al., Effect of impeller speed on mechanical and dissolution properties of high-shear granules. Chemical Engineering Journal, 2010. 164(2): p. 305-315.

3. Mangwandi, C., et al., High shear granulation of binary mixtures: Effect of powder composition on granule properties. Powder Technology, 2015. 270, Part B(0): p. 424-434.

4. Mangwandi, C., et al., Investigation of influence of process variables on mechanical strength, size and homogeneity of pharmaceutical granules produced by fluidised hot melt granulation. Powder Technology, 2015. 272: p. 173-180.

5. Mirza, Z., et al., Effect of impeller design on homogeneity, size and strength of pharmaceutical granules produced by high-shear wet granulation. Particuology, 2015. 23: p. 31-39.

6. Osorio-Fierros, A., et al., Influence of granulation process parameters on food tablet properties formulated using natural powders (Opuntia ficus and Chlorella spp.). Powder Technology, 2017. 317: p. 281-286.

7. Bowden-Green, B. and L. Briens, An investigation of drum granulation of biochar powder. Powder Technology, 2016. 288: p. 249-254.

8. Chen, H., C. Mangwandi, and D. Rooney, Production of solid biofuel granules from drum granulation of bio-waste with silicate-based binders. Powder Technology, 2019. 354: p. 231-239.

9. Djuris, J. and Z. Djuric, Modeling in the quality by design environment: Regulatory requirements and recommendations for design space and control strategy appointment. International Journal of Pharmaceutics, 2017. 533(2): p. 346-356.

10. Mangwandi, C., et al., An investigation of the influence of process and formulation variables on mechanical properties of high shear granules using design of experiment. International Journal of Pharmaceutics, 2012. 427(2): p. 328-336.

11. Mangwandi, C., et al., Optimisation of high shear granulation of multicomponent fertiliser using response surface methodology. Powder Technology, 2013. 238: p. 142-150.

12. Mangwandi, C., et al., Design, production and characterisation of granular adsorbent material for arsenic removal from contaminated wastewater. Chemical Engineering Research and Design, 2016. 110: p. 70-81.

13. Manzon, D., et al., Quality by Design: Comparison of Design Space construction methods in the case of Design of Experiments. Chemometrics and Intelligent Laboratory Systems, 2020. 200: p. 104002.

14. Navamanisubramanian, R., et al., Quality by design approach for optimization of repaglinide buccal tablets using Box-Behnken Design. Future Journal of Pharmaceutical Sciences, 2018. 4(2): p. 265-272.

15. Arsiccio, A. and R. Pisano, Application of the Quality by Design Approach to the Freezing Step of Freeze-Drying: Building the Design Space. Journal of Pharmaceutical Sciences, 2018. 107(6): p. 1586-1596. 
16. Kan, S., et al., A quality by design (QbD) case study on enteric-coated pellets: Screening of critical variables and establishment of design space at laboratory scale. Asian Journal of Pharmaceutical Sciences, 2014. 9(5): p. 268-278.

17. Kayrak-Talay, D., et al., Quality by design for wet granulation in pharmaceutical processing: Assessing models for a priori design and scaling. Powder Technology, 2013. 240: p. 7-18.

18. Rosas, J.G., et al., Quality by design approach of a pharmaceutical gel manufacturing process, part 1: Determination of the design space. Journal of Pharmaceutical Sciences, 2011. 100(10): p. 4432-4441.

19. Franceschinis, E., et al., High shear mixer granulation using food grade binders with different thickening power. Food Research International, 2014. 64: p. 711717.

20. Tikhonova, I.N., et al., Harnessing the Capabilities of Spray Granulation in the Food Industry for the Production of Functional Foods. Procedia Chemistry, 2014. 10: p. 419-423.

21. Mattenberger, H., et al., Sewage sludge ash to phosphorus fertiliser (II): Influences of ash and granulate type on heavy metal removal. Waste Management, 2010. 30(8): p. 1622-1633.

22. Mangwandi, C., et al., Alternative method for producing organic fertiliser from anaerobic digestion liquor and limestone powder: High Shear wet granulation. Powder Technology, 2013. 233: p. 245-254.

23. Mangwandi, C., et al., Development of a value-added soil conditioner from high shear co-granulation of organic waste and limestone powder. Powder Technology, 2014. 252: p. 33-41.

24. Silva, F.C., et al., Use of biomass ash-based materials as soil fertilisers: Critical review of the existing regulatory framework. Journal of Cleaner Production, 2019. 214: p. 112-124.

25. Iveson, S.M., et al., Nucleation, growth and breakage phenomena in agitated wet granulation processes: a review. Powder Technology, 2001. 117(1): p. 3-39.

26. Ojile, J.E., C.B. Macfarlane, and A.B. Selkirk, Drug distribution during massing and its effect on dose uniformity in granules. International Journal of Pharmaceutics, 1982. 10(2): p. 99-107.

27. van den Dries, K. and H. Vromans, Relationship between inhomogeneity phenomena and granule growth mechanisms in a high-shear mixer. International Journal of Pharmaceutics, 2002. 247(1-2): p. 167-177.

28. Zhou, Y.C., A.B. Yu, and J. Bridgwater, Segregation of binary mixture of particles in a bladed mixer. Journal of Chemical Technology \& Biotechnology, 2003. 78(2-3): p. 187-193.

29. Oka, S., et al., The effects of improper mixing and preferential wetting of active and excipient ingredients on content uniformity in high shear wet granulation. Powder Technology, 2015. 278: p. 266-277.

30. Adam, S., et al., An integrated Quality by Design (QbD) approach towards design space definition of a blending unit operation by Discrete Element Method (DEM) simulation. European Journal of Pharmaceutical Sciences, 2011. 42(1): p. 106115.

31. van den Dries, K., et al., Granule breakage phenomena in a high shear mixer; influence of process and formulation variables and consequences on granule homogeneity. Powder Technology, 2003. 133(1): p. 228-236. 
32. Alian, M., F. Ein-Mozaffari, and S.R. Upreti, Analysis of the mixing of solid particles in a plowshare mixer via discrete element method (DEM). Powder Technology, 2015. 274: p. 77-87.

33. Basinskas, G. and M. Sakai, Numerical study of the mixing efficiency of a batch mixer using the discrete element method. Powder Technology, 2016. 301: p. 815829.

34. Gentzler, M., J.N. Michaels, and G.I. Tardos, Quantification of segregation potential for polydisperse, cohesive, multi-component powders and prediction of tablet die-filling performance -A methodology for practical testing, re-formulation and process design. Powder Technology, 2015. 285: p. 96-102.

35. Gong, S., et al., Numerical simulation of wet particle flows in an intensive mixer. Powder Technology, 2019. 346: p. 301-315.

36. Laurent, B.F.C. and P.W. Cleary, Comparative study by PEPT and DEM for flow and mixing in a ploughshare mixer. Powder Technology, 2012. 228: p. 171-186.

37. Oka, S., et al., Diminished segregation in continuous powder mixing. Powder Technology, 2017. 309: p. 79-88.

38. Chang, K.H., et al., Effects of chemical and organic fertilizers on the growth, flower quality and nutrient uptake of Anthurium andreanum, cultivated for cut flower production. Scientia Horticulturae, 2010. 125(3): p. 434-441.

39. Chandratilleke, G.R., et al., A particle-scale index in the quantification of mixing of particles. AIChE Journal, 2012. 58(4): p. 1099-1118.

40. Lacey, P.M.C., Developments in the theory of particle mixing. Journal of Applied Chemistry, 1954. 4(5): p. 257-268.

41. Mangwandi, C., et al., The variability in nutrient composition of Anaerobic Digestate granules produced from high shear granulation. Waste Management, 2013. 33(1): p. 33-42.

42. Chitu, T.M., D. Oulahna, and M. Hemati, Wet granulation in laboratory-scale high shear mixers: Effect of chopper presence, design and impeller speed. Powder Technology, 2011. 206(1): p. 34-43.

43. Wade, J.B., G.P. Martin, and D.F. Long, The evolution of granule fracture strength as a function of impeller tip speed and granule size for a novel reversephase wet granulation process. International Journal of Pharmaceutics, 2015. 488(1): p. 95-101.

44. Rumpf, H., The Strength of Granules and Agglomeration, in Agglomeration, W.A. Knepper, Editor. 1962, John Wiley: New York. p. 379-418.

45. Cavinato, M., et al., Combining formulation and process aspects for optimizing the high-shear wet granulation of common drugs. International Journal of Pharmaceutics, 2011. 416(1): p. 229-241.

46. Nguyen, T.H., W. Shen, and K. Hapgood, Effect of formulation hydrophobicity on drug distribution in wet granulation. Chemical Engineering Journal, 2010. 164(2): p. 330-339.

47. Radl, S., et al., Mixing characteristics of wet granular matter in a bladed mixer. Powder Technology, 2010. 200(3): p. 171-189.

48. Farber, L., G. Tardos, and J.N. Michaels, Use of X-ray tomography to study the porosity and morphology of granules. Powder Technology, 2003. 132(1): p. 57-63.

49. Rahmanian, N., et al., Characterisation of granule structure and strength made in a high shear granulator. Powder Technology, 2009. 192(2): p. 184-194.

50. Verkoeijen, D., et al., Determining granule strength as a function of moisture content. Powder Technology, 2002. 124(3): p. 195-200. 


\section{Nomenclature}

$\begin{array}{ll}A & \text { Coded (normalised) binder content(-) } \\ B & \text { Coded (normalised) teawaste fraction (-) } \\ B C & \text { Binder concentration (g/L) } \\ b_{i} & \text { Coefficient } \\ C & \text { Coded (normalised) impeller speed(-) } \\ C_{b} & \text { Binder content in the granule (-) } \\ D & \text { Coded (normalised) liquid to solid ratio(-) } \\ D P & \text { De-mixing potential (\%) } \\ d_{p} & \text { Surface - average particle diameter (m) } \\ d_{t} & \text { Mean granule size at after a granulation time of } t(\text { mm) } \\ E & \text { Coded (normalised) granulation time (-) } \\ G T & \text { Granulation time (seconds) } \\ L F & \text { Fraction of the light particles in the simulation (-) } \\ L S & \text { Liquid/solid ratio (-) } \\ O & \text { Impeller speed (rpm) } \\ p & \text { Fraction of component I in the sample (-) } \\ T F & \text { Teawaste fraction (-) } \\ V_{\text {Total }} & \text { Total voxels in the sample(-) } \\ V_{\text {void }} & \text { Number of voxels that are void (-) }\end{array}$

\section{Greek symbols}

$\begin{array}{ll}\varepsilon & \text { Granule porosity (-) } \\ \kappa & \text { Material constant in Eq. } 11 \\ \theta & \text { Liquid-solid contact angle }\left(^{\circ}\right) \\ \gamma_{L V} & \text { Is liquid surface tension } \\ \lambda & \text { Is the liquid pore saturation (-) } \\ \sigma & \text { Granule tensile strength }\left(\mathrm{N} / \mathrm{m}^{2}\right)\end{array}$


Table 1 Summary of experiments variables

\begin{tabular}{lcccc}
\hline Batch No. & BC (-) & TF $(-)$ & O (rpm) & LS (-) \\
\hline E1-1 to E1-6 & -1 & -1 & -1 & +1 \\
E2-1 to E2-6 & +1 & -1 & -1 & +1 \\
E3-1 to E3-6 & -1 & -1 & -1 & -1 \\
E4-1 to E4-6 & -1 & +1 & -1 & -1 \\
E5-1 to E5-6 & -1 & -1 & +1 & -1 \\
E6-1 to E6-6 & -1 & +1 & +1 & +1 \\
E7-1 to E7-6 & -1 & -1 & +1 & -1 \\
E8-1 to E8-6 & -1 & +1 & +1 & -1 \\
E9-1 to E9-6 & +1 & -1 & -1 & +1 \\
E10-1 to E10-6 & +1 & +1 & -1 & +1 \\
E11-1 to E11-6 & +1 & -1 & -1 & -1 \\
E12-1 to E12-6 & +1 & +1 & -1 & -1 \\
E13-1 to E13-6 & +1 & -1 & +1 & +1 \\
E14-1 to E14-6 & +1 & +1 & +1 & +1 \\
\hline
\end{tabular}




\begin{tabular}{lllll}
\hline E15-1 to E15-6 & +1 & -1 & +1 & -1 \\
E16-1 to E16-6 & +1 & +1 & +1 & -1 \\
\hline
\end{tabular}


Table 2 Summary of elements concentration in different kinds of powder

\begin{tabular}{cccc}
\hline & Limestone & Teawaste & Lignosulfonate \\
\hline Calcium $(\mathrm{mg} / \mathrm{g})$ & 290.48 & 3.116 & 1.966 \\
Sodium $(\mathrm{mg} / \mathrm{g})$ & 0.1054 & 0.0918 & 84.18 \\
\hline
\end{tabular}


Table 3 Parameters used in simulation

\begin{tabular}{ccccc}
\hline Case & $\begin{array}{c}\text { Number of light } \\
\text { particles }\end{array}$ & $\begin{array}{c}\text { Number of } \\
\text { heavy particles }\end{array}$ & $\begin{array}{c}\text { No. Fraction } \\
\text { of light particles }\end{array}$ & O (rpm) \\
\hline 1 & 1800 & 4200 & 0.3 & 103 \\
2 & 3600 & 2400 & 0.6 & 103 \\
3 & 1800 & 4200 & 0.3 & 158 \\
4 & 3600 & 2400 & 0.6 & 158 \\
\hline
\end{tabular}


Table 4 Coefficients of the Equation (9)

\begin{tabular}{lccccccc}
\hline & $b_{0}$ & $b_{1}$ & $b_{2}$ & $b_{3}$ & $b_{4}$ & $b_{5}$ & $b_{6}$ \\
\hline$d_{30}$ & 2.11 & 0.16 & -0.73 & -0.20 & 0.39 & -0.10 & -0.32 \\
$d_{60}$ & 1.91 & 0.16 & -0.78 & -0.21 & 0.45 & -0.11 & -0.37 \\
$d_{90}$ & 1.76 & 0.17 & -0.79 & -0.17 & 0.39 & -0.097 & -0.35 \\
$d_{120}$ & 1.60 & 0.17 & -0.70 & -0.12 & 0.37 & -0.10 & -0.31 \\
$d_{150}$ & 1.48 & 0.18 & -0.64 & -0.14 & 0.34 & -0.13 & -0.29 \\
$d_{180}$ & 1.31 & 0.084 & -0.51 & -0.11 & 0.28 & -0.034 & -0.23 \\
\hline
\end{tabular}


Table 5 ANOVA table for response of granule mean size at the end point of 90 seconds

\begin{tabular}{cccccc}
\hline Source & Sum of Square & $\mathrm{d}_{\mathrm{f}}$ & Mean Square & F value & P value \\
\hline Model & 7.97 & 6 & 1.33 & 189.05 & $<0.0001$ \\
$A-B C$ & 0.3 & 1 & 0.3 & 43.01 & 0.0003 \\
$B-T F$ & 6.62 & 1 & 6.62 & 942.04 & $<0.0001$ \\
$C-O$ & 0.4 & 1 & 0.4 & 57.12 & 0.0001 \\
$D-L S$ & 1.58 & 1 & 1.58 & 225.27 & $<0.0001$ \\
$A B$ & 0.099 & 1 & 0.099 & 14.14 & 0.0071 \\
$B D$ & 1.33 & 1 & 1.33 & 189.15 & $<0.0001$ \\
Residual & 0.049 & 7 & $7.03 * 10^{-03}$ & & \\
Cor Total & 8.02 & 13 & & & \\
\hline
\end{tabular}


Table 6 ANOVA table for response of granule strength

\begin{tabular}{cccccc}
\hline Source & Sum of Square & $\mathrm{d}_{\mathrm{f}}$ & Mean Square & F value & P value \\
\hline Model & 172.81 & 7 & 24.69 & 29.40 & $<0.0001$ \\
$A-B C$ & 95.39 & 1 & 95.39 & 113.61 & $<0.0001$ \\
$B-T F$ & 11.93 & 1 & 11.93 & 14.21 & 0.0012 \\
$D-L S$ & 1.47 & 1 & 1.47 & 1.76 & 0.2001 \\
$E-G T$ & 2.84 & 1 & 2.84 & 3.39 & 0.0806 \\
$A B$ & 7.62 & 1 & 7.62 & 9.07 & 0.0069 \\
$A E$ & 1.48 & 1 & 1.48 & 1.77 & 0.1988 \\
$B D$ & 0.99 & 1 & 0.99 & 1.18 & 0.2904 \\
Residual & 16.79 & 20 & 0.84 & & \\
Cor Total & 189.60 & 27 & & & \\
\hline
\end{tabular}


Table 7 Summary of experimental conditions and calculated binder content.

\begin{tabular}{ccccccc}
\hline $\begin{array}{c}\text { sample No. } \\
\text { Unit }\end{array}$ & $\begin{array}{c}\text { BC } \\
\mathrm{g} / 100 \mathrm{ml}\end{array}$ & $\begin{array}{c}\mathrm{TF} \\
-\end{array}$ & $\begin{array}{c}\mathrm{O} \\
\mathrm{rpm}\end{array}$ & $\begin{array}{c}\mathrm{LS} \\
-\end{array}$ & $\begin{array}{c}\mathrm{GT} \\
\mathrm{s}\end{array}$ & $\begin{array}{c}\text { calculated binder content } \\
\%\end{array}$ \\
\hline 1 & 20 & 0.6 & 158 & 0.3 & 30 & 13.50 \\
2 & 20 & 0.6 & 103 & 0.3 & 30 & 10.22 \\
3 & 40 & 0.6 & 103 & 0.25 & 180 & 25.50 \\
4 & 40 & 0.6 & 103 & 0.25 & 30 & 19.28 \\
5 & 20 & 0.3 & 103 & 0.3 & 30 & 4.65 \\
6 & 20 & 0.3 & 103 & 0.3 & 180 & 3.37 \\
7 & 20 & 0.3 & 158 & 0.25 & 30 & 3.81 \\
8 & 20 & 0.3 & 158 & 0.3 & 30 & 4.34 \\
\hline
\end{tabular}




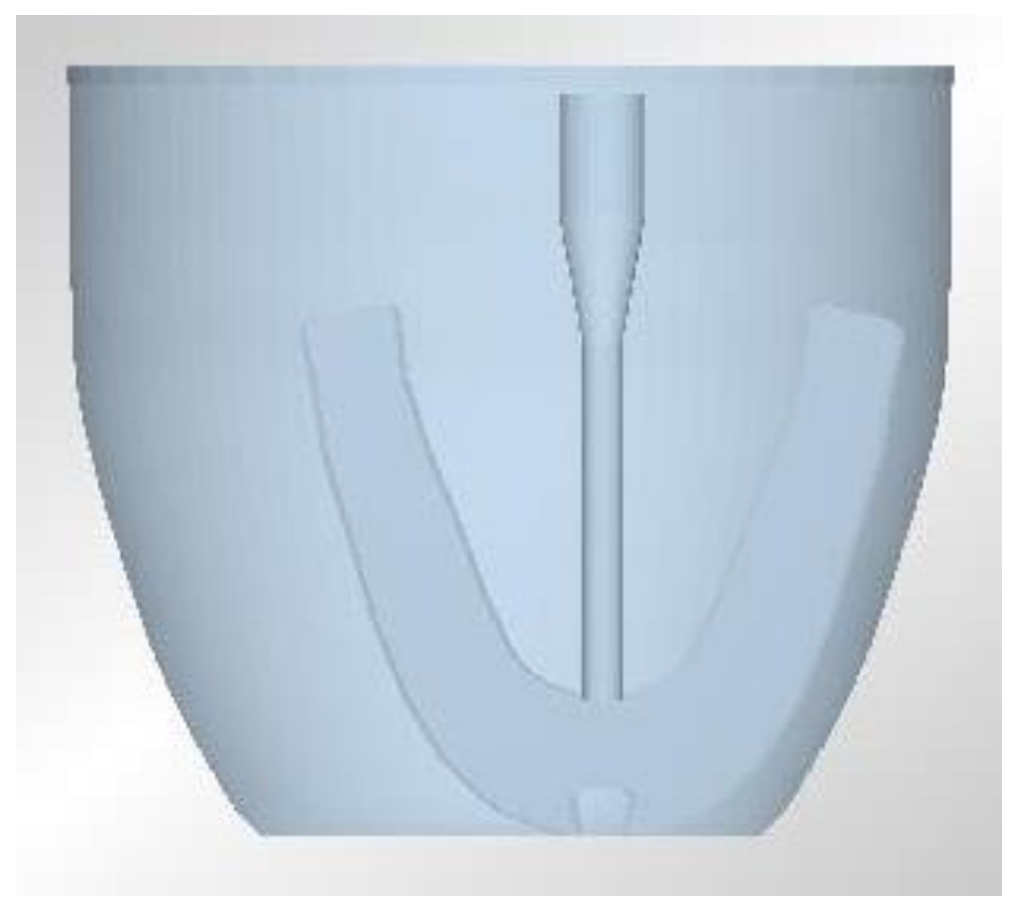

(a)

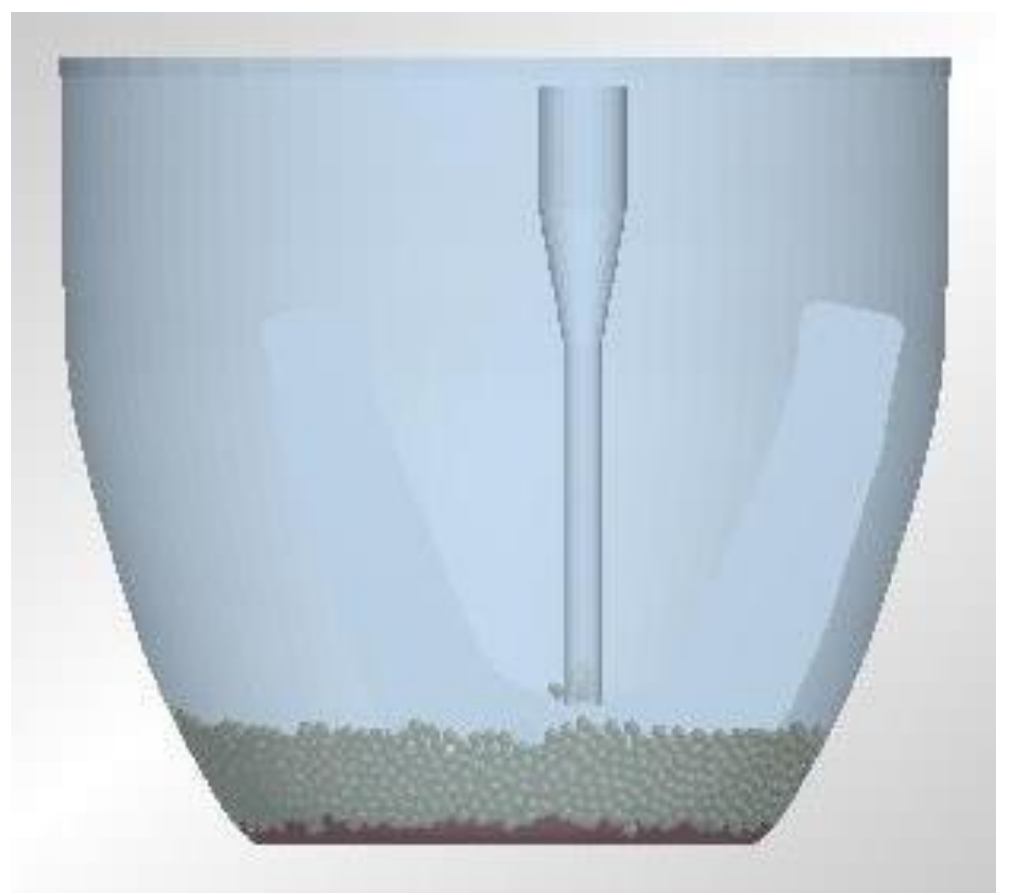

(b)

Figure 1 Schematic illiterates of vessel configuration (a) and initial loading of particles (b) 


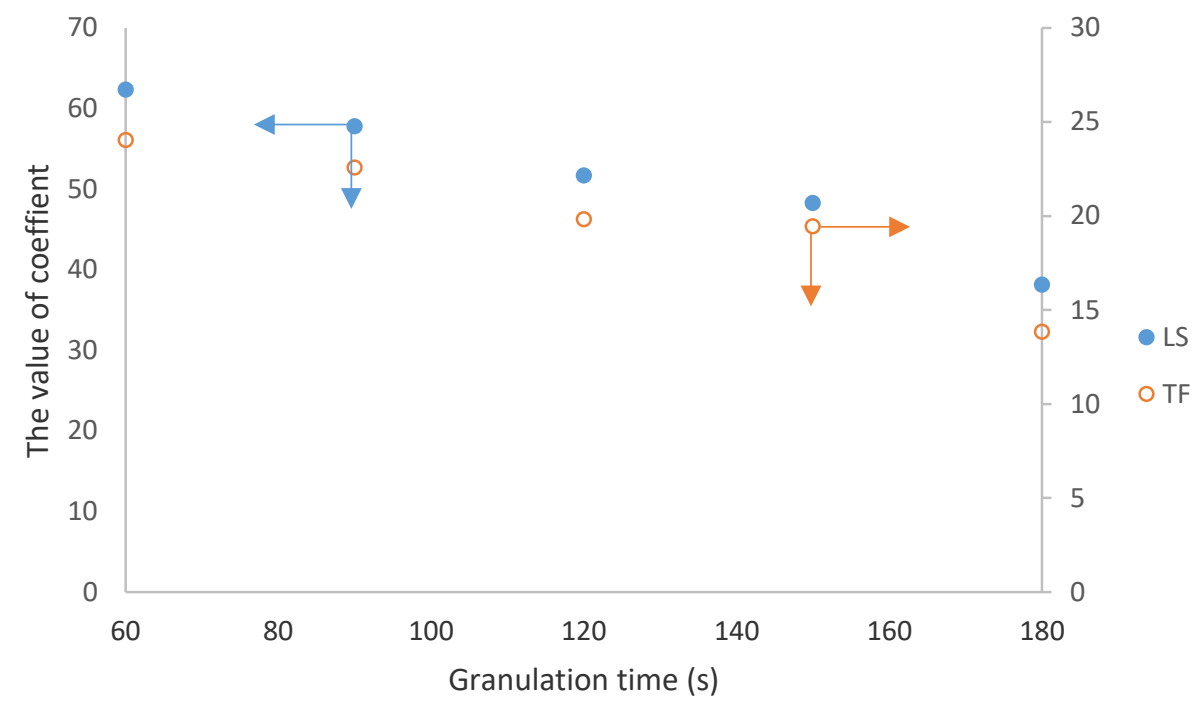

Figure 2 Summary of coefficients of TF and LS 


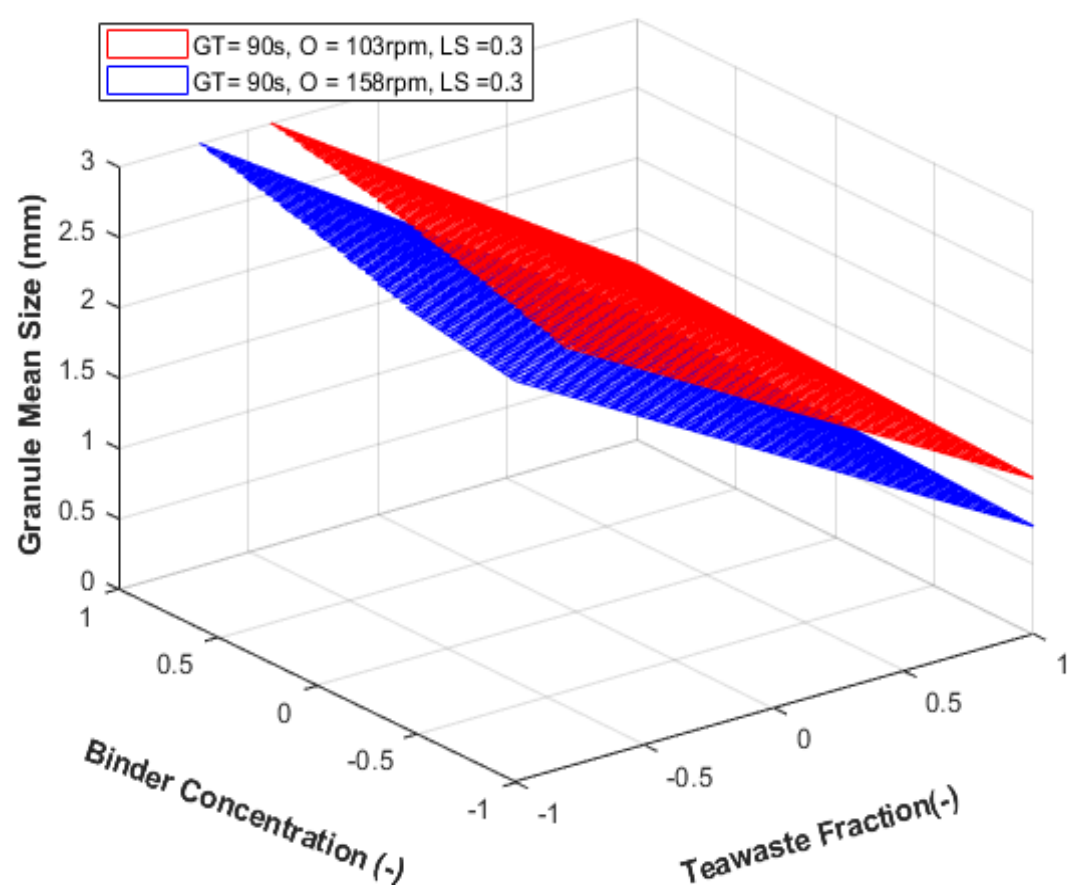

(a)

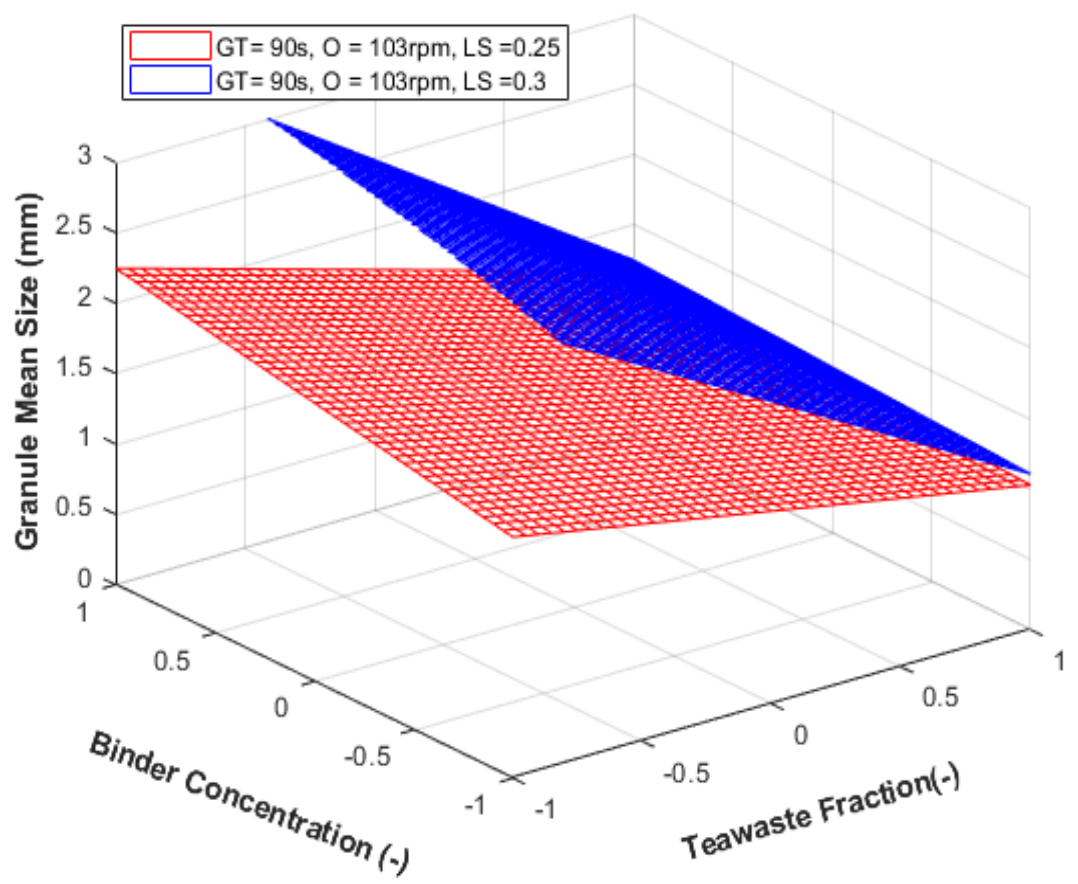

(b)

Figure 3 Surface plot showing effects of different variables on granule mean size 


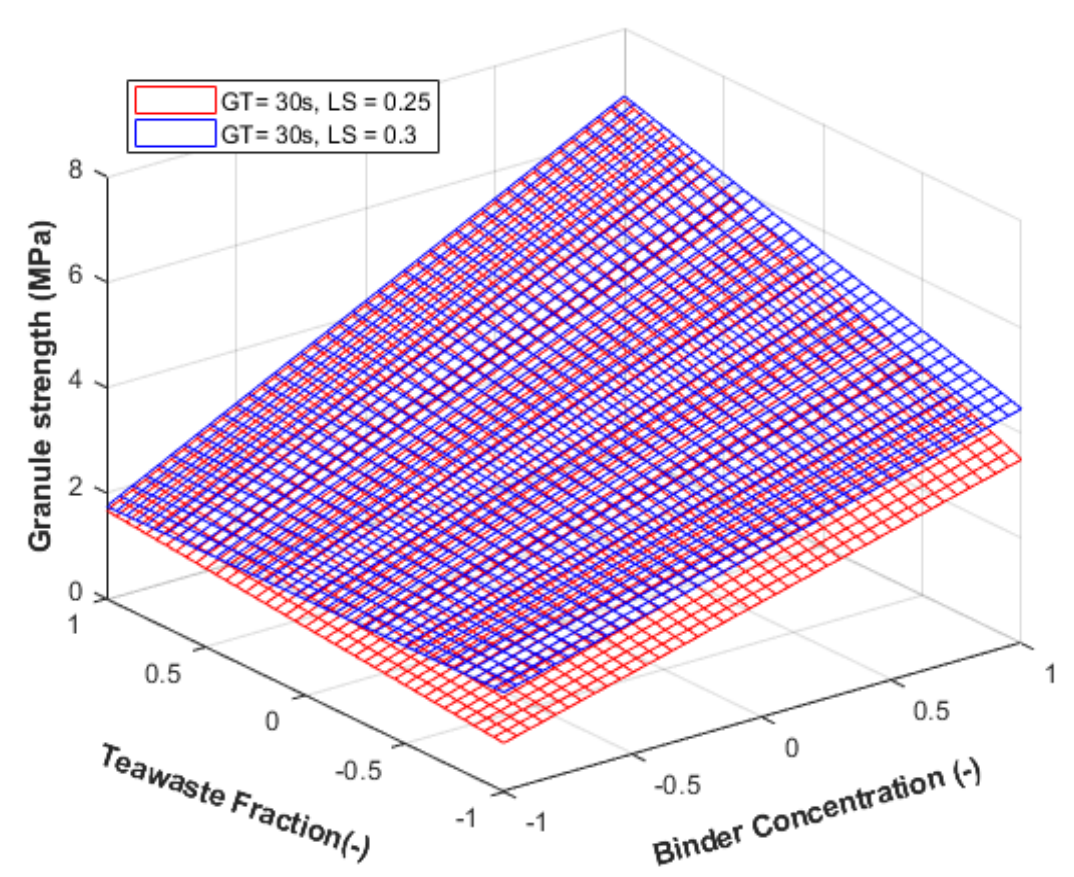

(a)

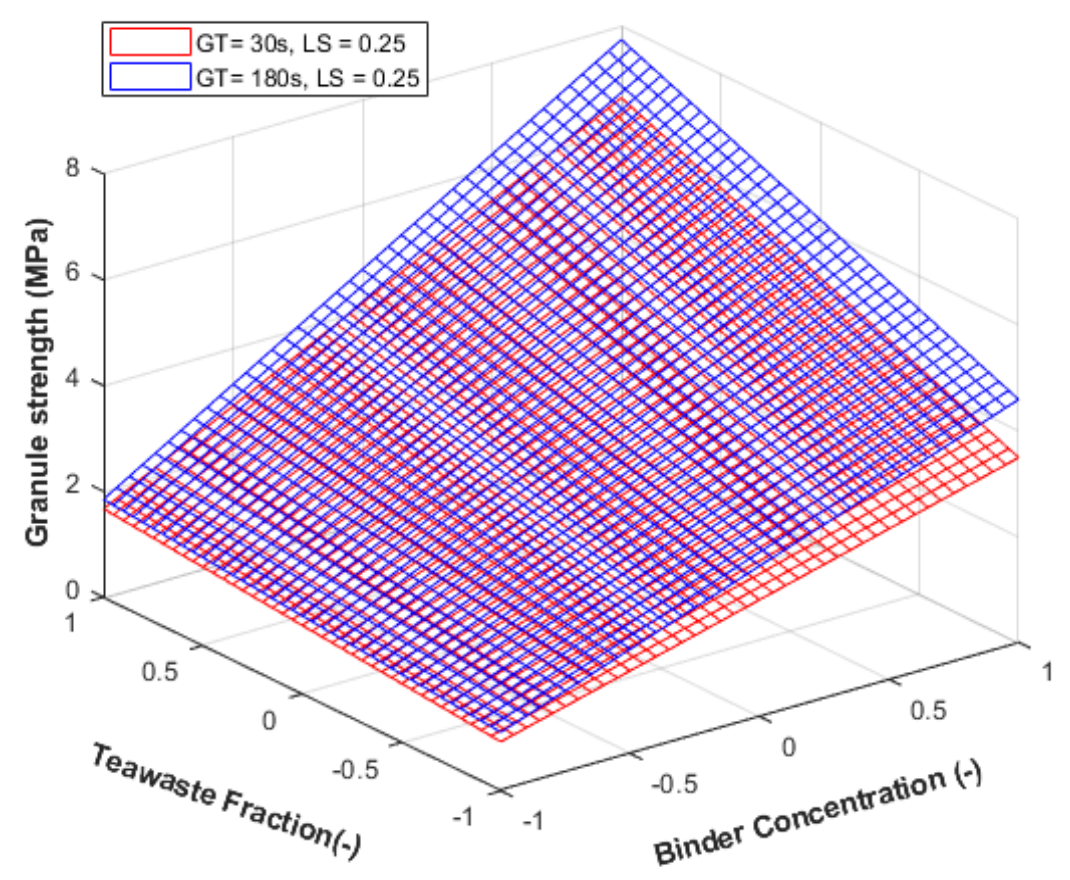

(b)

Figure 4 Surface plot showing effects of different variables on granule tensile strength 


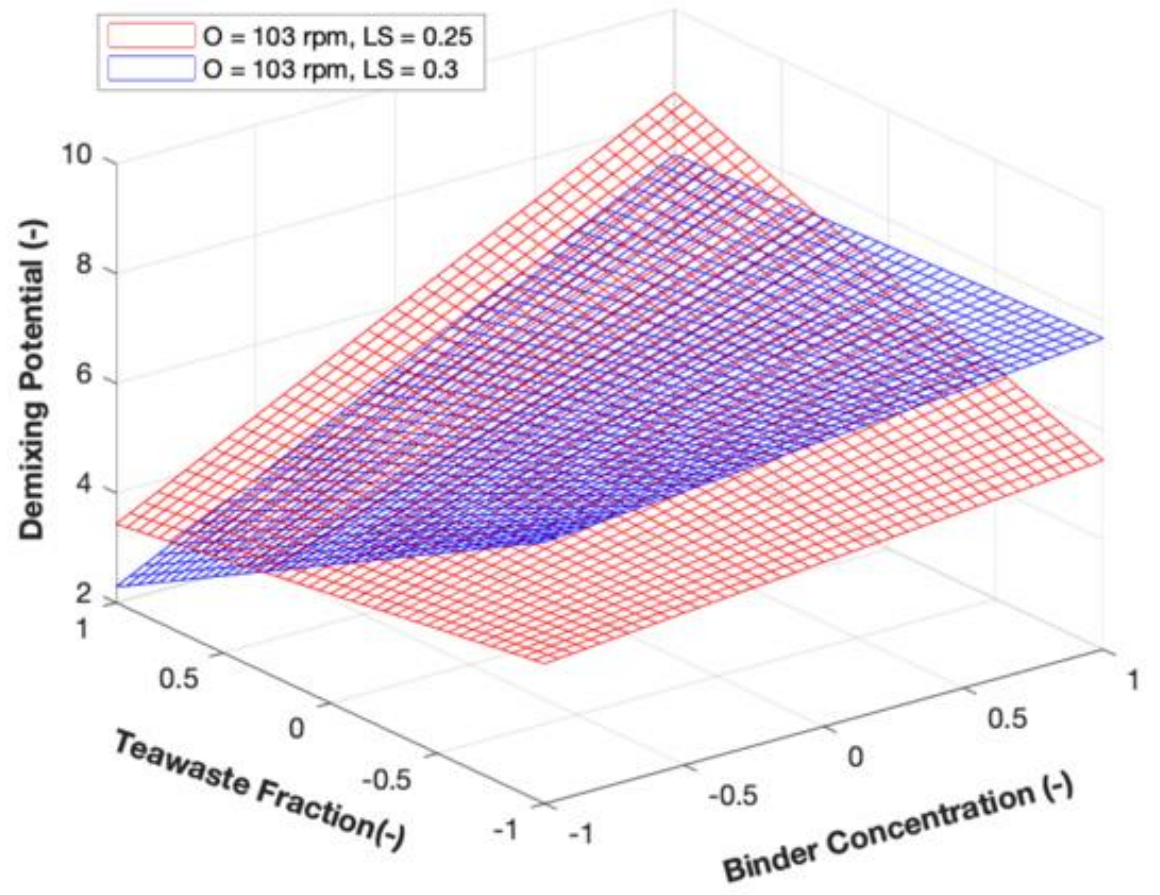

(a)

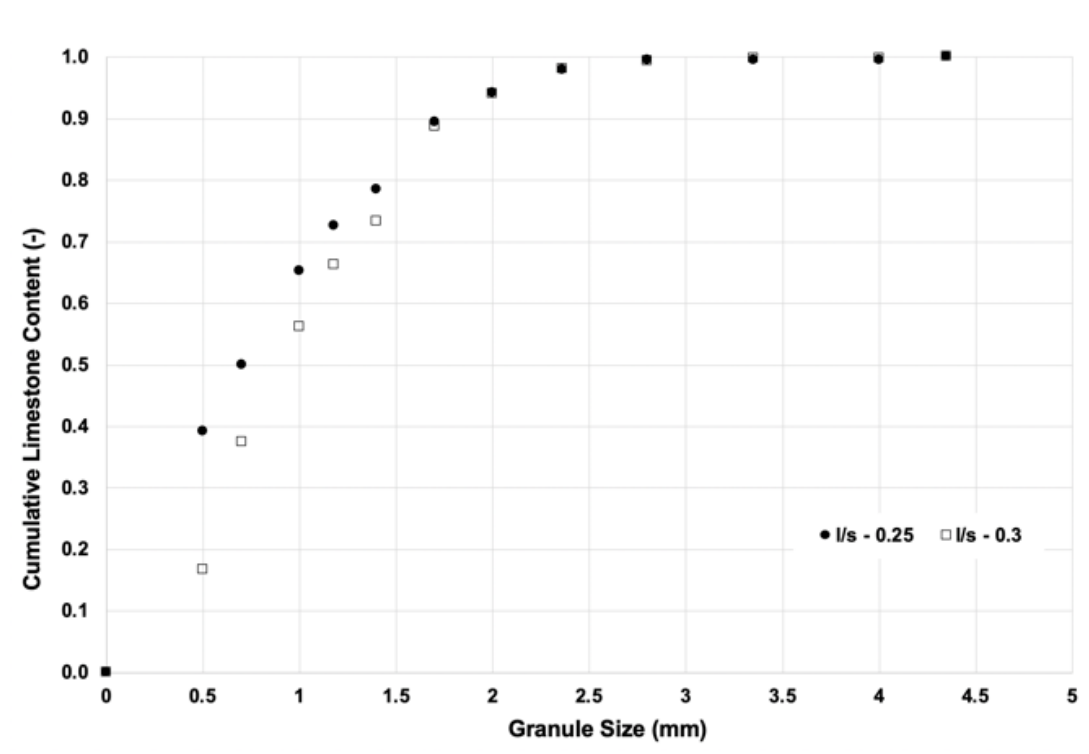

(b)

Figure 5(a) Surface plot showing effects of different variables on limestone de-mixing potential (b) The limestone content in the granule size fraction operated under different LS 


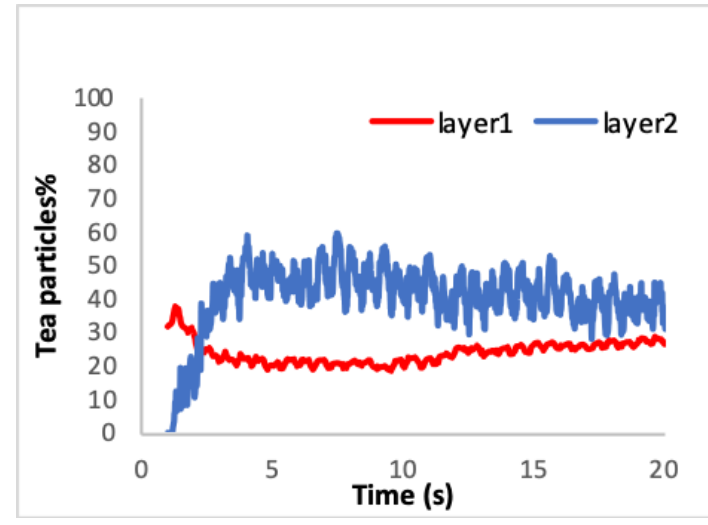

(a)

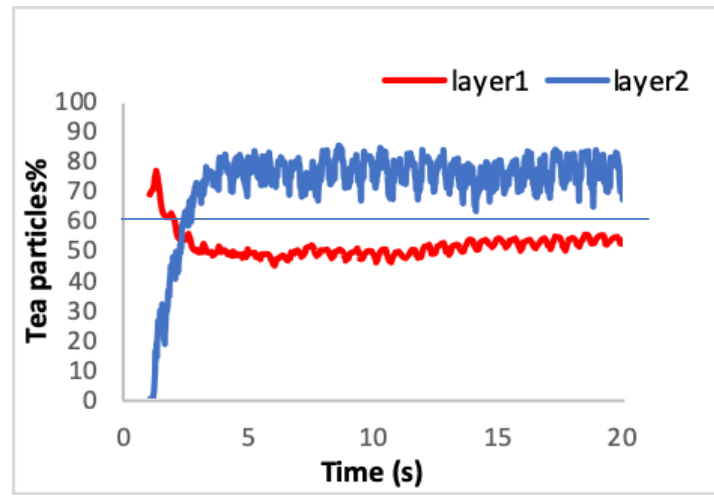

(c)

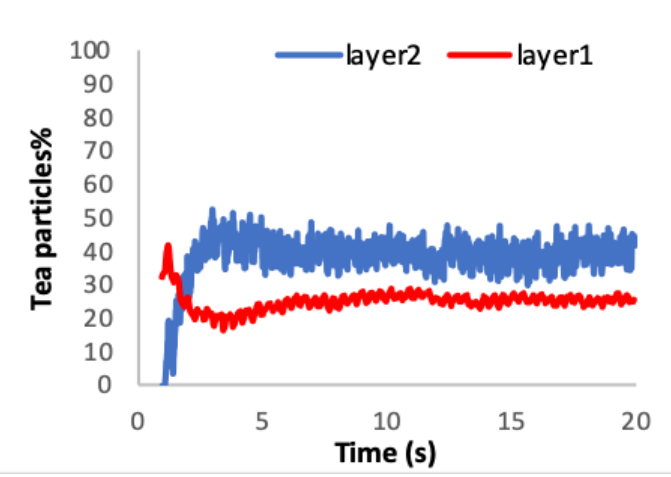

(b)

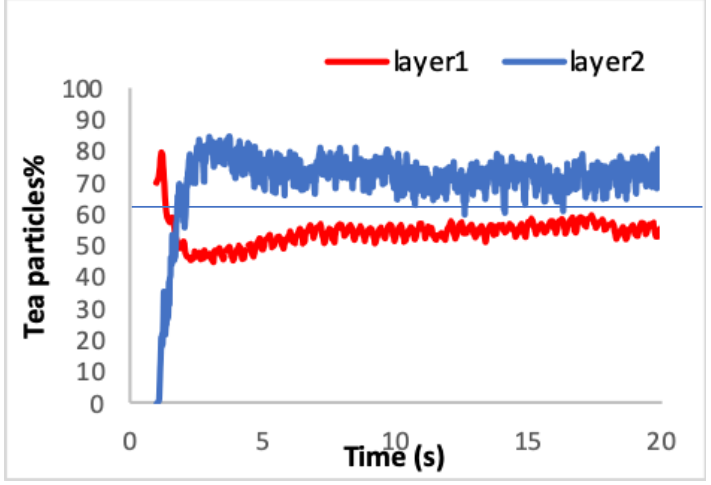

(d)

Figure 6 Percentage of teawaste in the top and bottom layer of the powder bed dry mixing obtained from DEM simulation ((a) O 103, TF 0.3 (b) O $158 \mathrm{rpm}$, TF 0.3 (c) O $103 \mathrm{rpm}$, TF 0.6 (d) O 158 rpm, TF 0.6.) 


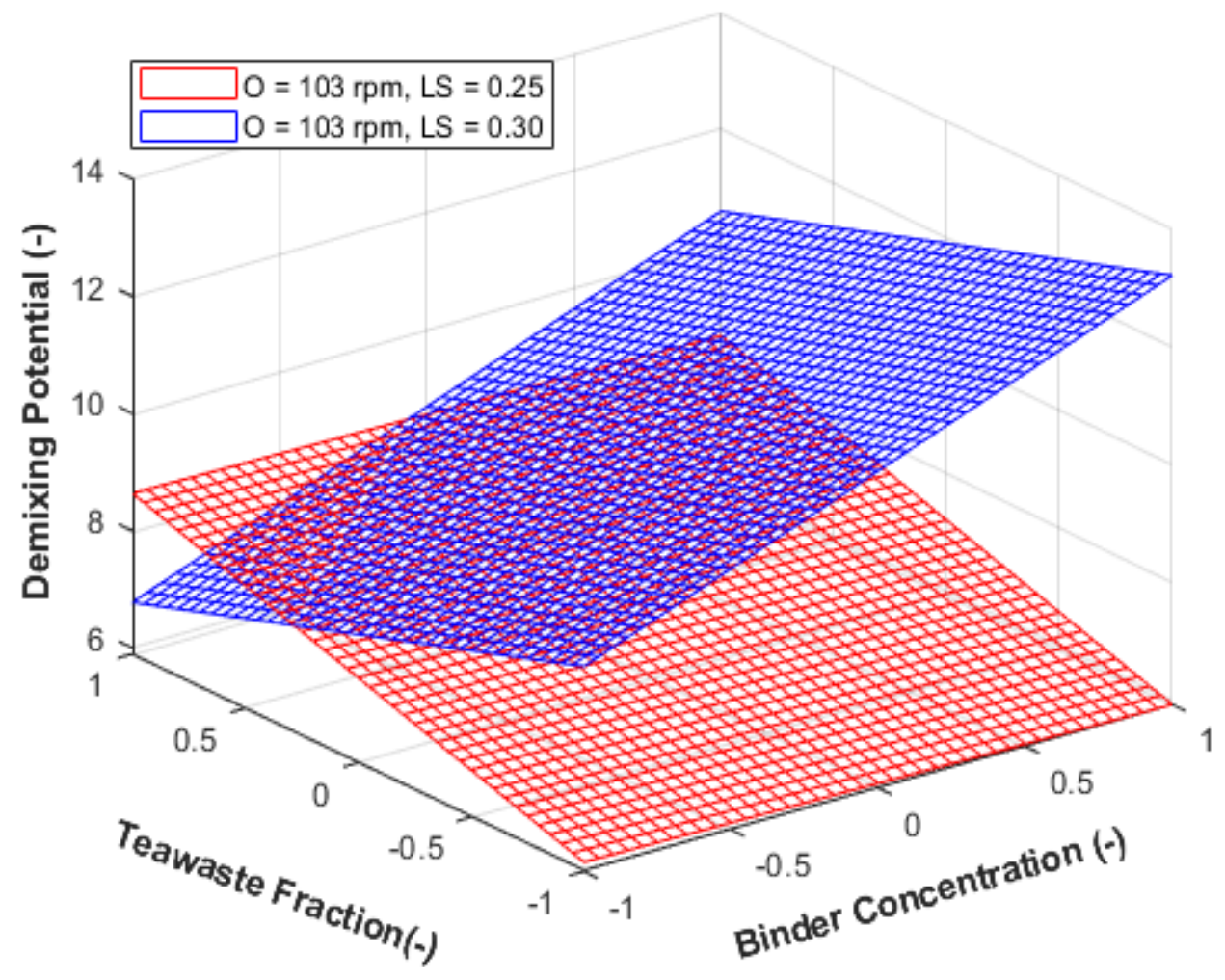

Figure 7 Surface plot showing effects of different variables on binder de-mixing potential 


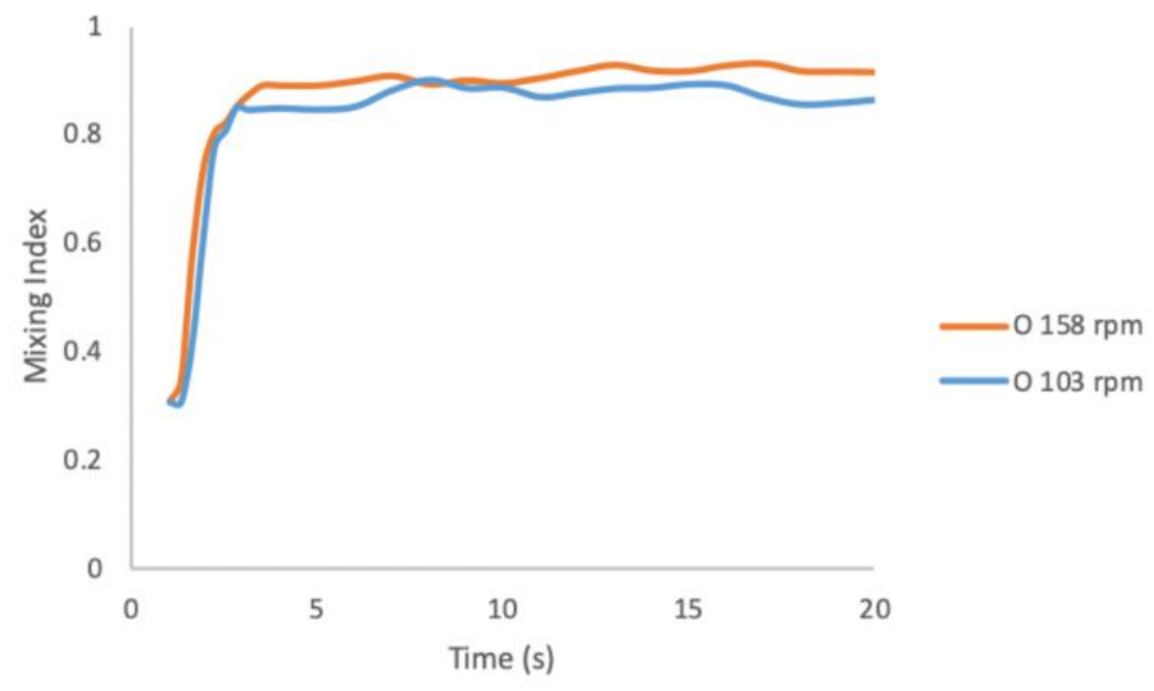

Figure 8 Mixing index versus time at different $\mathrm{O}$ (light particles fraction: 0.6) 


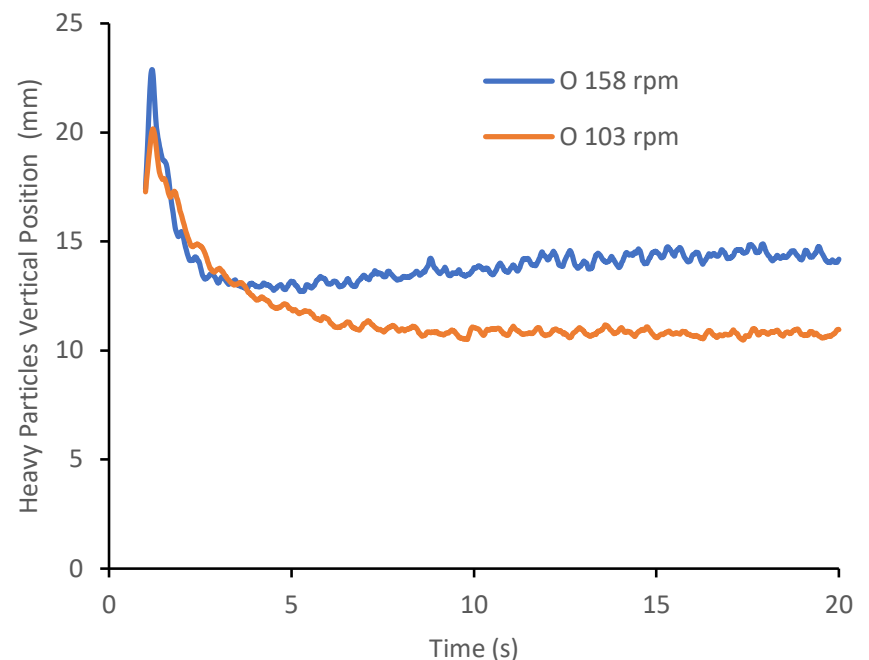

(a)

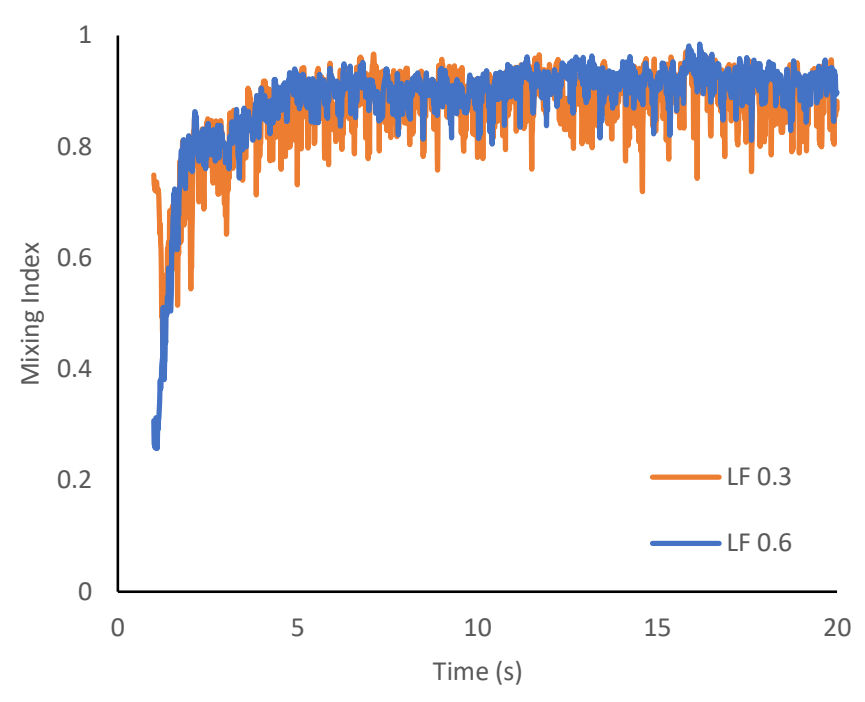

(b)

Figure 9(a) Heavy particles average vertical position (from bottom of the vessel) versus mixing time at different $\mathrm{O}$ (b) Mixing index versus time at different light particle fraction (O $158 \mathrm{rpm})$. 


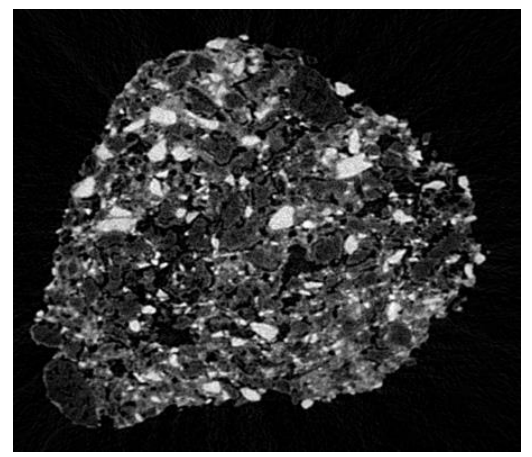

(a)

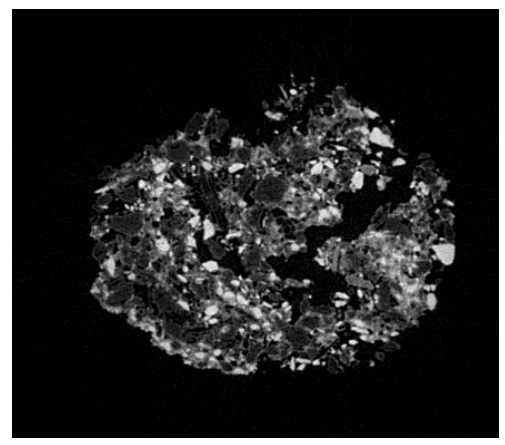

(d)

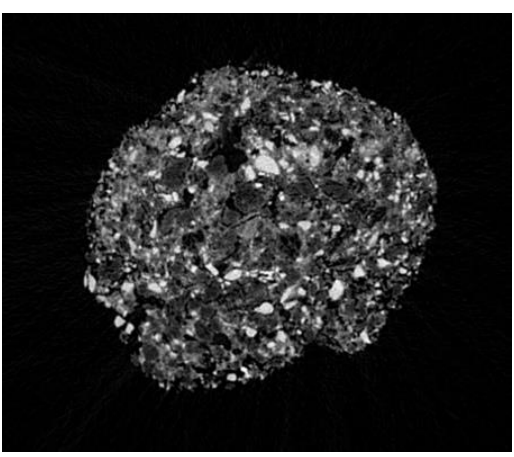

(b)

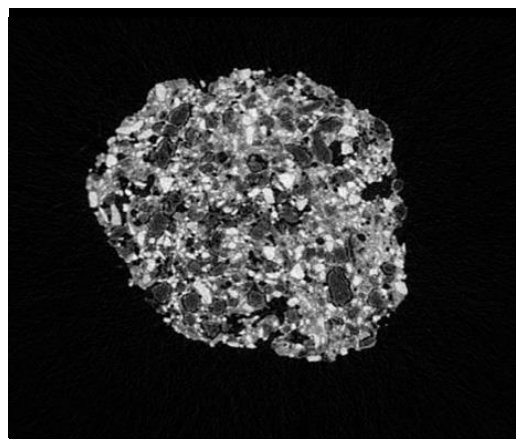

(e)

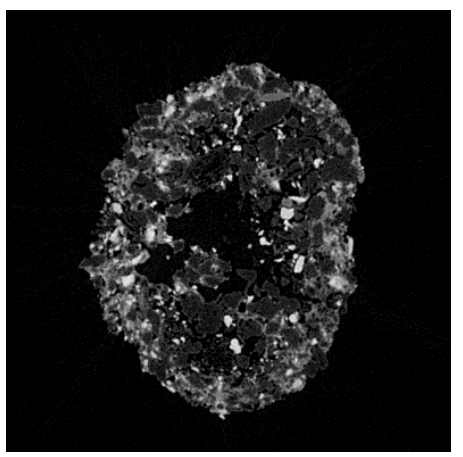

(c)

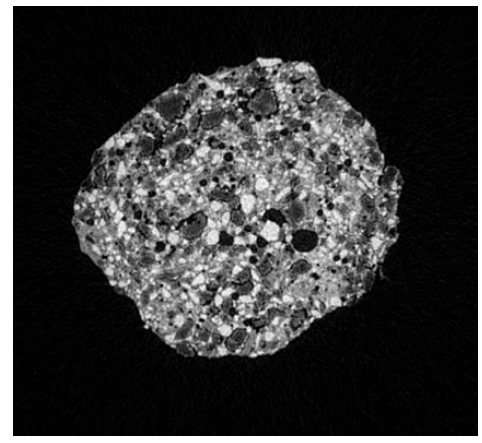

(f)

Figure 10 Central cross sections of samples at different O (a) $103 \mathrm{rpm}$ (b) $158 \mathrm{rpm}$, GT (c) 30 s (d) $180 \mathrm{~s}, \mathrm{LS}$ (e) 0.25 (f) 0.3 